\title{
A rational nomenclature for naming peptide toxins from spiders and other venomous animals
}

\author{
Glenn F. King ${ }^{1, *}$, Margaret C. Gentz ${ }^{1}$, Pierre Escoubas ${ }^{2}$, \\ and Graham M. Nicholson ${ }^{3}$
}

${ }^{1}$ Institute for Molecular Bioscience, University of Queensland, St Lucia, QLD 4072, Australia ${ }^{2}$ Institut de Pharmacologie Moléculaire et Cellulaire,

Centre National de la Recherche Scientifique, 06560 Valbonne, France

${ }^{3}$ Department of Medical \& Molecular Biosciences, University of Technology, Sydney Broadway NSW 2007, Australia

* Address for correspondence:

Institute for Molecular Bioscience, University of Queensland, 306 Carmody Road, St Lucia, QLD 4072, Australia

Phone: +61 7 3346-2025; Fax: +61 7 3346-2021; Email: glenn.king@imb.uq.edu.au 


\section{Summary}

Molecular toxinology research was initially driven by an interest in the small subset of animal toxins that are lethal to humans. However, the realization that many venomous creatures possess a complex repertoire of bioactive peptide toxins with potential pharmaceutical and agrochemical applications has led to an explosion in the number of new peptide toxins being discovered and characterized. Unfortunately, this increased awareness of peptide toxin diversity has not been matched by the development of a generic nomenclature that enables these toxins to be rationally classified, catalogued, and compared. In this article, we introduce a rational nomenclature that can be applied to the naming of peptide toxins from spiders and other venomous animals.

Keywords: peptide toxin; nomenclature; spider; scorpion; cone snail; sea anemone; snake 


\section{Introduction}

Scientists and lay public alike have been interested in the secretions from venomous animals for many centuries. However, the modern era of molecular toxinology did not begin until the 1960s and it was driven primarily by a desire to purify and understand the mechanism of action of lethal components from medically important animals such as marine cone snails (Whysner and Saunders, 1966), stonefish (Deakins and Saunders, 1967), and snakes (Sato et al., 1969).

The pioneering work of Baldomero Olivera, Michael Adams, Lourival Possani and others in the late 1980 s and early 1990 s led to the realization that most animal venoms comprise a complex cocktail of peptide and protein components of which the lethal toxin often represents only a minor proportion (Olivera, 1997; Possani et al., 2000; Adams, 2004). Moreover, it gradually became clear that many of the non-lethal venom components have useful bioactivities that enable them to be deployed as research tools, such as in the characterization of ion channels (Adams et al., 1993; McIntosh et al., 1999a; King, 2007; King et al., 2008), or as leads for the development of pharmaceutical agents (Harvey, 2002; Lewis and Garcia, 2003) and insecticides (Tedford et al., 2004b; Bosmans and Tytgat, 2007). This realization, combined with the development of more sophisticated venom fractionation techniques, advances in mass spectrometry (Escoubas, 2006; Favreau et al., 2006; Escoubas et al., 2008), and the ability to directly analyze toxin transcripts from venom-gland cDNA libraries (Kozlov et al., 2005; Sollod et al., 2005), has led to a rapid increase in rate of peptide toxin discovery during the past decade.

Unfortunately, this rapid expansion of the peptide toxin database has not been matched by the development of a rational nomenclature for naming these toxins. In this article, we demonstrate that the number of peptide toxin sequences being deposited in the protein and nucleic acid databases is growing exponentially, with the result that continued use of ad hoc naming schemes will introduce confusion and make it difficult to compare toxins and establish evolutionary 
relationships. We have therefore developed a rational nomenclature that imparts each toxin name with information about its origin and biological activity. We suggest that this nomenclature can be applied to the naming of peptide toxins from spiders and other venomous animals.

\section{Results and Discussion}

\subsection{Growth of the peptide toxin database}

We define peptide toxins as venom peptides with a molecular mass less than $10 \mathrm{kDa}$, which includes the vast majority of proteinaceous toxins from spiders, hymenopterans, cone snails, and scorpions (and a significant proportion of sea anemone and snake toxins). This cut-off value provides a clear distinction between the peptide toxins that dominate most animal venoms and larger enzymes and haemostatic factors from snakes, for which an established nomenclature already exists (Meier and Stocker, 1992).

We have used the Tox-Prot database (Jungo and Bairoch, 2005) in order to examine the rate of discovery of peptide-toxins. While there are more comprehensive sequence databases available for peptide toxins from scorpions (Tan et al., 2006) and cone snails (Haas et al., 2007), the ToxProt database allows an objective historical comparison of the rate of discovery of peptide toxins from different venomous animals. Figure 1 shows the growth in peptide-toxin discovery during the period 1967-2006. We have defined the year of discovery as the date in which a particular peptide sequence was first published, patented, or deposited in Swiss-Prot (Boeckmann et al., 2003). The number of peptide-toxin sequences isolated from sea anemones, cone snails, scorpions, and spiders has grown exponentially over the past decade (Fig. 1A-D), whereas the number of peptide toxins isolated from snakes has grown only linearly since 1970 (Fig. 1E).

If one considers only peptide toxins from sea anemones, cone snails, scorpions, and spiders, the cumulative total number of sequences has been growing exponentially since 1985 (Fig. 1F). 
Based on an extrapolation of this exponential rate of increase, the number of the peptide toxins isolated from these animals alone is expected to grow from 1,111 in 2006 to 4,500 by 2015 and $\sim 24,000$ by 2025 (Fig. 2). However, these projections are likely to be underestimates and they fall well short of the millions of unique sequences projected to be present in the venoms of these animals (Table 1). The ability to sequence toxins directly from mass spectrometric analysis of venoms (Escoubas et al., 2008), as well as initiatives to sequence the genomes of venomous animals (Menez et al., 2006; Putnam et al., 2007), will further accelerate the rate of peptide toxin discovery over the next decade. Thus, in order to facilitate future cataloguing and analysis, it is imperative that a rational nomenclature be developed for naming these peptide toxins.

\subsection{Extant schemes for naming peptide toxins}

Several attempts have been made previously to develop a rational nomenclature for naming venom proteins. For example, in 1991, the International Society for Toxinology (IST) established a Nomenclature Committee to develop a standardized nomenclature for naming toxins from plants, bacteria, and venomous animals (Meier and Stocker, 1992). A survey of IST members carried out by this committee (Meier and Stocker, 1992) indicated that $98 \%$ of respondents favoured development of a standardized toxin nomenclature but, almost two decades later, no such system has been formulated. As a result, numerous different methods have been employed to name peptide toxins. As outlined in the following sections, these range from ad hoc schemes that contain no information about function or species of origin to more rational nomenclatures based on toxin origin, function, molecular scaffold, or some combination of these parameters.

\subsubsection{Ad hoc naming schemes}

The relatively small number of lethal proteinaceous toxins purified from venomous animals in the earliest period of molecular toxinology research were typically named in an ad hoc fashion, usually by concatenating some derivative of the genus or species name with the word "toxin". For 
example, the lethal peptide toxin from the Sydney funnel-web spider Atrax robustus was named robustoxin (Sheumack et al., 1985), whereas the toxic protein from the black widow spider Latrodectus tredecimguttatus was named $\alpha$-latrotoxin (Tzeng and Siekevitz, 1978). While this ad hoc approach to naming toxins provides information about the biological origin of the peptide, it has the potential to cause confusion. For example, the lethal toxin from the Blue Mountains funnel-web spider Hadronyche versuta was named versutoxin (Brown et al., 1988), even though this peptide is an ortholog of robustoxin from Atrax robustus (34/42 residues are identical). Not surprisingly, these toxins have the same three-dimensional (3D) fold (Fletcher et al., 1997a; Pallaghy et al., 1997) and biological activity (Nicholson et al., 1994; Nicholson et al., 1998).

Many peptide toxins have been given trivial names based on their order of elution during a chromatographic separation procedure, such as DW13.3 (Sutton et al., 1998) and Tx4(6-1) (de Figueiredo et al., 1995). This type of naming scheme provides minimal information content with no clues about the animal from which the toxins were isolated nor their mode of action. In some cases, initials identifying the source genus and species have been attached to the toxin name, such as in the case of the ASIC1a blocker PcTx1 from the tarantula Psalmopoeus cambridgei (Escoubas et al., 2000). While this type of naming scheme helps with source identification, it provides no information about the molecular target of the toxin and begs the question of what name to use for other toxins isolated from the same animal, including possible paralogs.

\subsubsection{Nomenclature based on primary structure and molecular target}

The most comprehensive sequence-based toxin nomenclature is that developed by Tygat and coworkers (Tytgat et al., 1999), which is derived from an earlier scheme developed by Miller (Miller, 1995), for naming scorpion peptides that modulate the activity of voltage-activated potassium $\left(\mathrm{K}_{\mathrm{V}}\right)$ channels. In this scheme, scorpion peptides active on $\mathrm{K}_{\mathrm{V}}$ channels are grouped into one of 20 families (designated $\alpha-K T x 1$ through $\alpha$-KTx20) based on amino acid sequence 
motifs plus the location of the cysteine residues that establish the 3D fold of the toxins (Tytgat et al., 1999; Rodriguez de la Vega and Possani, 2004; Abdel-Mottaleb et al., 2006). Toxins within the same family are distinguished by additional numerical descriptors. For example, within the $\alpha$ KTx1 family, charybdotoxin and iberiotoxin are named $\alpha-\mathrm{KTx} 1.1$ and $\alpha-\mathrm{KTx} 1.3$, respectively.

This nomenclature has the advantage of being inherently simple and the grouping into 20 toxin families recapitulates the phylogeny of the toxins (Tytgat et al., 1999; Rodriguez de la Vega and Possani, 2004). However, it has several drawbacks as a generic naming scheme. First, the toxin name contains no information about its biological origin. Second, because the secondary withinfamily descriptor is largely arbitrary and based on order of discovery, paralogs and orthologs that differ by only one or two amino acid residues might be given names that disguise their close evolutionary relationship. For example, it would not be immediately obvious that a charybdotoxin paralog named $\alpha-\mathrm{KTx} 1.25$ was a close relative of $\alpha-\mathrm{KTx} 1.1$ (charybdotoxin). Finally, the activity prefixes (e.g., $\alpha$ for $K_{V}$ blockers) might cause confusion since they have been assigned without reference to previous use in other groups of venomous animals. Thus, while this scheme is very useful for classifying peptide toxins, it has disadvantages as a generic naming scheme.

The problem with arbitrary assignment of activity descriptors (and this is a widespread problem in the field) is that they conflict with use of identical descriptors with different biological inference that are used for naming toxins from other venomous animals. For example, scorpion $\alpha$-toxins target voltage-activated sodium $\left(\mathrm{Na}_{\mathrm{V}}\right)$ channels (Possani et al., 1999), $\alpha$-conotoxins target nicotinic acetylcholine receptors (McIntosh et al., 1999b), scorpion $\alpha-\mathrm{KTx}$ toxins target $\mathrm{K}_{\mathrm{V}}$ channels (Tytgat et al., 1999), and $\alpha$-agatoxins are polyamines that block mammalian glutamate receptors (Adams, 2004). The non-uniform (and up until now largely arbitrary) use of activity descriptors highlights why it is important to develop a rational nomenclature before the database becomes too large to allow systematic revision of toxin names. 


\subsubsection{Nomenclature based on species of origin, cystine scaffold, and molecular target}

The most comprehensive toxin nomenclature is that developed by Olivera and others for naming cystine-rich peptide toxins from marine cone snails (Conus spp.) (McIntosh et al., 1999b). This scheme has the advantage of providing information about the toxin's biological origin, cystine framework (which determines its 3D fold), and molecular target. In this nomenclature, the toxin name begins with a Greek symbol that identifies its molecular target (if known). For example, $\omega$ and $\boldsymbol{\kappa}$ are used to identify peptides that block voltage-activated calcium $\left(\mathrm{Ca}_{\mathrm{V}}\right)$ and $\mathrm{K}_{\mathrm{V}}$ channels, respectively. This symbol is followed an uppercase letter identifying the species of origin. Because cone snails constitute a single genus (Conus), this is often sufficient to identify the species. Thus, $\mathbf{P}$ and $\mathbf{G}$ denote $C$. purpurascens and C. geographus, respectively. In cases where two distinct Conus species names begin with the same letter, additional lowercase letters are added to avoid confusion. Thus, $\mathbf{G m}$ is used to distinguish C. gloriamaris from C. geographus.

The species identifier is followed by a Roman numeral that identifies the cystine framework of the toxin. Framework definitions are based on the number of Cys residues, intercystine spacing, and the pattern of disulfide connectivities. For example, framework IV defines the six-cysteine pattern $\mathrm{C}_{1} \mathrm{C}_{2}-\mathrm{C}_{3}-\mathrm{C}_{4}-\mathrm{C}_{5}-\mathrm{C}_{6}$ with disulfide connectivity $\mathrm{C}_{1}-\mathrm{C}_{5}, \mathrm{C}_{2}-\mathrm{C}_{3}$, and $\mathrm{C}_{4}-\mathrm{C}_{6}$, where the dash indicates a variable number of residues in the intercystine loops. Toxin paralogs with the same cystine framework are discriminated by an uppercase letter following the framework identifier. Thus, w-conotoxin MVIIA, MVIIB, MVIIC, and MVIID are paralogous $\mathrm{Ca}_{\mathrm{V}}$ channel blockers from C. magus that have framework VII and very similar sequences. The framework identifiers have evolved in an ad hoc fashion and they do not provide information per se about the number of cystines, nor their connectivity. Moreover, this ad hoc method of defining cystine frameworks has in some cases introduced confusion since some frameworks that were initially thought to be different and hence given different names (e.g., I and II) were later shown to be identical. Alternative methods of defining conotoxin frameworks have been suggested (Olivera, 2002). 
Unfortunately, this rational conotoxin nomenclature has not been applied to Conus peptides that have only one or no disulfide bonds. For historical reasons, these peptides are generally referred to as conopeptides rather than conotoxins and they have been named in an ad hoc manner (e.g., contulakin, conopressin, and conantokin). In theory, however, there is no reason why a unified nomenclature could not be systematically applied to both linear and disulfide-rich peptide toxins.

\subsubsection{Nomenclature based on species of origin and molecular target}

The realization over a decade ago that there are likely to be well over one million unique spider toxins led us to develop a rational nomenclature for naming these peptides (Fletcher et al., 1997b; King et al., 2002). This nomenclature was derived from the scheme described above for naming conotoxins, except that information about cystine framework was excluded because of the paucity of information about spider-toxin scaffolds at that point in time.

This nomenclature begins with a Greek symbol, which is based on those previously used for naming conotoxins, that identifies the molecular target of the toxin (if known). This is followed by a generic toxin name based on the genus, subfamily, or family name of the spider or group of spiders. For example, toxins from Australian mouse spiders (Missulena spp.) are known generically as missulenatoxins (MSTXs) (Gunning et al., 2003). This part of the toxin name is more important for spider toxins than those from cone snails since cone snails comprise a single genus whereas spiders comprise $>40,000$ species in more than 3,600 genera (Platnick, 1997). Moreover, spider taxonomy is in considerable flux and one has to be cautious in choosing the generic toxin name. For example, Australian funnel-web spiders currently comprise two separate genera (Atrax and Hadronyche) within the subfamily Atracinae (Gray, 1988). Thus, in order to avoid confusion as a result of future taxonomic revisions, these peptides were named atracotoxins (ACTXs) based on the subfamily name rather than one of the genera (Fletcher et al., 1997b). 
The generic toxin name is followed by an uppercase letter that identifies the genus of origin and a lowercase letter that identifies the species. Both genus and species designators are required to avoid confusion because of the vast number of spider species and the complications caused by the same group of spiders being assigned to more than one genus. The genus/species designators are followed by a number that designates a particular family of paralogous toxins with the biological function indicated by the activity descriptor. This designator was introduced because often there is more than one group of toxins from the same species that act on the same molecular target. This designator is simply incremented as new groups of toxins are discovered. For example, the first group of $\mathrm{Ca}_{\mathrm{v}}$ channel blockers isolated from the venom of the Blue Mountains funnel-web spider Hadronyche versuta were named $\omega$-ACTX-Hv1 toxins whereas a subsequent group of $\mathrm{Ca}_{\mathrm{v}}$ blockers isolated from the same spider, which have evolved from a different gene and which have a substantially different 3D structure, were named $\omega$-ACTX-Hv2 toxins (Wang et al., 2001).

The toxin-family designator is followed by a lowercase letter that is used to distinguish homologs (also called isoforms). This designator is critical because of the combinatorial library strategy that spiders and other venomous animals have employed to diversify their toxin repertoire (Sollod et al., 2005). That is, rather than producing "one-off" versions of each toxin, spiders typically express a small family of 3-6 homologs that can differ by as little as one or a few amino acid residues (Tedford et al., 2004b). Hence, from an evolutionary perspective, it is helpful if the toxin name conveys the relationship between homologous toxins in a facile manner. For example, six $\omega$-ACTX-Hv1 homologs have been isolated thus far from $H$. versuta and they were named $\omega-$ ACTX-Hv1a through $\omega$-ACTX-Hv1f based on this nomenclature (Wang et al., 1999).

This rational but simple nomenclature solved the confusion that was caused by use of the names versutoxin and robustoxin for the very similar orthologous lethal toxins from $H$. versuta and A. robustus, respectively. These toxins were renamed $\delta$-ACTX-Hv1a and $\delta$-ACTX-Ar1a 
(Fletcher et al., 1997a), which rapidly conveys the knowledge that these toxins are orthologs and that they both target $\mathrm{Na}_{\mathrm{V}}$ channels (Nicholson et al., 2004).

\subsection{Development of a rational nomenclature for naming peptide toxins}

\subsubsection{Key criteria for development of a generic toxin nomenclature}

In developing a rational nomenclature for naming peptide toxins one has to consider the diverse groups of researchers who study or use toxins. While most toxinologists have a broad interest in the structure, function, and evolution of toxins, physiologists and pharmacologists are primarily interested in the molecular target of the toxin while molecular geneticists may be more concerned with phylogenetic relationships and the genetic mechanisms for evolving toxin diversity. Thus, in any rational nomenclature for naming peptide toxins, the toxin name should, at minimum, include information about the biological origin of the peptide as well as its molecular target and/or biological function (if known). In addition, the name should facilitate rapid searching of electronic databases for toxins from different venomous animals that act on the same or similar molecular target, and it should allow inferences to be drawn about possible evolutionary relationships (e.g., paralogs and orthologs).

Structural biologists are also interested in peptide toxins as they often present novel 3D folds not found outside of venomous animals. In addition, they can serve as structural templates for medicinal chemists for the rational design of drugs (Lewis and Garcia, 2003; Clark et al., 2005; Armishaw et al., 2006) and insecticides (Froy et al., 1999b; Maggio and King, 2002; Cohen et al., 2004; Tedford et al., 2004a). However, classifying toxins on the basis of 3D structure is very difficult, largely because structures have not been determined for the vast majority of peptide toxins. Thus, it will be many years before we have even a rudimentary understanding of the complete range of 3D scaffolds that have been recruited into venom peptidomes. Hence, while it might be desirable for a toxin's name to provide information about its 3D fold, or even simply its 
disulfide architecture, this is a difficult task and should only be done if it provides useful information without introducing confusion.

\subsubsection{Proposed nomenclature for naming peptide toxins}

The nomenclature we propose for naming peptide toxins, regardless of whether they contain disulfide bonds or not, is outlined in Figure 3. It is a simple extension of the nomenclature we developed earlier for naming spider toxins (Fletcher et al., 1997b), as described in Section 2.2.4.

Broad activity descriptor: The toxin name should begin with a Greek letter or other symbol denoting its biological activity or molecular target. These activity descriptors, which are summarized in Table 2, were chosen to be as parsimonious as possible. Wherever a conflict existed between extant activity descriptors, we gave precedence to the descriptor used for naming conotoxins, since this is the most widely used rational nomenclature. Thus, for example, we propose that scorpion $\alpha$-toxins, which target $\mathrm{Na}_{\mathrm{V}}$ channels, should be renamed $\delta$ or $\mu$ toxins since these Greek symbols have been widely used to describe both spider and cone snail toxins that modify the activity of $\mathrm{Na}_{\mathrm{V}}$ channels (see Table 2). In Table 2, we introduce a number of new activity descriptors to account for recently discovered toxins with novel activities. For example, we propose the use of $\pi$ to designate toxins such as PcTx1 (Escoubas et al., 2000) and APETx2 (Diochot et al., 2004) that target acid-sensing ion channels (ASICs) and $\phi$ to denote toxins such as maurocalcine (Fajloun et al., 2000) that target ryanodine receptors. In addition, we have introduced activity descriptors for a variety of 7TM receptors such as the endothelin, neurotensin, octopamine, and vasopressin receptors (see Table 2).

Rather than targeting a specific receptor or ion channel, many peptide toxins (primarily those without disulfide bonds) have nonspecific cytolytic activity via their ability to interact with, and disrupt, lipid membranes (Anderluh and Macek, 2002; Kuhn-Nentwig, 2003). In order to develop 
a unified nomenclature that includes all peptide toxins, we have introduced a new activity descriptor $(\Delta)$ for this group of cytolytic peptides. In addition, we propose that the activity descriptor $\mathbf{U}$ be used for toxins for which the primary biological activity has not yet been identified. Although seemingly trivial, this is an important descriptor since many toxins identified from sequencing cDNA/EST libraries will initially not have an identified biological activity. Where there is more than one family of toxins with unknown activity from a single species, then these can be discriminated by adding a subscript to the activity indicator (i.e., $\mathrm{U}_{1}, \mathrm{U}_{2}, \mathrm{U}_{3}$, etc.).

It is likely that new activity indicators will have to be introduced in future as new toxins are discovered with novel activities. However, the comprehensive list of activity indicators in Table 2 should suffice for the vast majority of peptide toxins.

Descriptor for receptor and ion channel subtypes: Many peptide toxins have become useful pharmacological probes because of their ability to discriminate between different ion channel and receptor subtypes. Unfortunately, however, information about the subtype-specificity of toxins is rarely incorporated into their names. We propose that this can be readily accomplished by incorporating a subscript after the broad activity descriptor that refers to the primary receptor or ion channel subtype that is targeted by the toxin. Whenever possible, these subscripts should follow the International Union of Pharmacology (IUPHAR) recommendations for vertebrate receptor and ion channel subtypes as outlined in the 2007 Guide to Receptors and Channels (Alexander et al., 2007). Thus, for example, a toxin that specifically targeted $\mathrm{K}_{\mathrm{V}} 1.3$ channels (e.g., ShK) would be given the prefix $\kappa_{1.3}$, whereas a toxin that targeted endothelin receptor $\mathrm{B}$ (e.g., sarafotoxin S6c) would be given the prefix $\xi_{\mathrm{B}}$. If the subtype specificity of a toxin is not known, or if it is broadly active against all subtypes of the molecular target, then only the broad activity descriptor should be used, without the subscript denoting subtype specificity. 
Toxin name: The activity descriptor should be followed by a name that is common to all toxins from a single venomous family, regardless of the species, so that taxonomic relationships between toxins can be quickly established. Surprisingly, with several notable exceptions such as the conotoxins (Gray et al., 1981) and atracotoxins (Fletcher et al., 1997b), this has not been common practice. For example, toxins from the scorpion Leiurus quinquestriatus have been given a variety of trivial names such as charybdotoxin (Miller et al., 1985), 18-2 (Marshall et al., 1994), and Lq2 (Lu and MacKinnon, 1997), which makes it impossible without consulting the literature to establish that these toxins all derive from the same source.

Since cone snails comprise a single genus, Conus, it makes sense to continue to use the generic term conotoxin (abbreviated CTX) to describe peptide toxins from marine cone snails. However, the situation is considerably more complex for scorpions, sea anemones, snakes, and spiders which comprise $\sim 175,68,328$, and $>3,600$ genera, respectively [see (Platnick, 1997) and the Integrated Taxonomic Information System at http://www.itis.gov/index.html]. For these animals, using toxin names based on genus would cause confusion (since it would be exceedingly difficult to keep track of more than 4,000 generic toxin names!) and it would disguise the evolutionary relationship between orthologous toxins. Moreover, since taxonomy is generally more stable at the family level as opposed to the genus level, a nomenclature based on family rather than genus should be less susceptible to future taxonomic revisions. Thus, for venomous animals other than marine cone snails, we propose that the toxin name should be based on the taxonomic family rather than the genus. This considerably simplifies the naming scheme since snakes, scorpions, sea anemones, and spiders comprise only 18, 18, 48, and 108 families, respectively.

Devising generic names based on taxonomic family rather than genus has the additional advantage of highlighting evolutionary relationships between toxins. To give an example, toxins from the spider genera Macrothele and Hadronyche have been named Magi toxins and 
atracotoxins (ACTXs), respectively. However, these hexathelid spiders are closely related, and it is clear that many of the toxins isolated from these spiders are orthologs, a fact completely disguised by their very different names. For example, as illustrated in Fig. 4, Magi-14 (Satake et al., 2004) and $\delta$-ACTX-Hvla (Fletcher et al., 1997a) are 70\% identical and have the same cystine framework; they are clearly derived from the same ancestral gene. Thus, we propose that toxins derived from these two genera, as well as all other genera within the taxonomic family Hexathelidae, be named hexatoxins (HXTXs). Thus, $\delta$-ACTX-Hvla from Hadronyche versuta and Magi-14 from Macrothele gigas would be renamed $\delta$-HXTX-Hv1a and $\delta$-HXTX-Mg1a, respectively. The revised names immediately reveal that these toxins are orthologs and that they both target $\mathrm{Na}_{\mathrm{V}}$ channels.

We have developed a complete list of generic toxin names (and corresponding abbreviations) for all extant families of snakes, spiders, scorpions, and sea anemones. These names were developed based on the following criteria:

(i) The generic toxin name should be as short as possible

(ii) Generic toxin names should all be sufficiently different to avoid potential confusion

(iii) The abbreviations for these toxin names should comprise no more than five letters and, in accordance with longstanding convention, they should end with the letters "TX".

(iv) Toxin abbreviations must be unique, with no overlap between groups of venomous animals

(v) To avoid confusion, names and abbreviations in current use should be avoided

Criterion (v) is important, and it required exhaustive literature searches to fulfill. For example, although exotoxin and lipotoxin would appear to be suitable names for toxins from the sea anemone families Exocoelactiidae and Liponematidae, respectively, these names are currently 
used for bacterial toxins and thus should be avoided. We therefore chose the generic names coelatoxin and liponetoxin, respectively, for toxins from these two families of sea anemones. We have also avoided names that might invoke a broader meaning, such as isotoxin, microtoxin, megatoxin, and pseudotoxin, as well as toxin abbreviations in common use such as SRTX (sarafotoxin), ACTX (atracotoxin), and MSTX (missulenatoxin). We purposefully avoid threeletter abbreviations for generic toxin names in order to avoid confusion with extant abbreviations such as BTX (batrachotoxin), CTX (conotoxin and ciguatoxin), DTX (dendrotoxin), LTX (latrotoxin), and STX (saxitoxin).

In order to minimize the extent of name revisions required by the proposed nomenclature, we were able in several cases to chose generic toxin names that were initially developed to describe toxins from certain genera, but for which the definition can be readily expanded to include toxins from all species within the same taxonomic family. For example, the name agatoxin has been used for almost 20 years to describe peptide toxins from the spider genus Agelenopsis (Bindokas and Adams, 1989; Adams, 2004), which is a member of the family Agelenidae. Thus, we propose that all toxins derived from species within Agelenidae be named agatoxins in order to avoid major revision of the names of the widely used and studied agatoxins. Similarly, the definition of lycotoxin, which was originally used to describe toxins from spider genus Lycosa (Yan and Adams, 1998), can be extended to include all toxins derived from the spider family Lycosidae, in which Lycosa resides. We have also extended the definition of the name plectoxin (abbreviated PLTX), which is commonly used to describe toxins from the spider genus Plectreurys, to include all toxins from the spider family Plectreuridae.

The proposed generic names for peptide toxins from snakes, scorpions, sea anemones, and spiders are given in Supplementary Tables 1-4 and they are reproduced for convenience at http://www.venomics.org/nomenclature. Using iterative rounds of naming and revision, we were 
able to devise a unique set of abbreviations that comprise only four letters for $94 \%$ of these 192 taxonomic families (including all scorpion, sea anemone, and snake families).

Genus and species descriptors: While the toxin name alone should be sufficient to identify the family from which a toxin derives, an additional descriptor is necessary to distinguish different species within each family. This descriptor is important for source identification since, in many cases, there will be tens or even hundreds of different species within each family. The most extreme case is the spider family Linyphiidae, which comprises 4329 species in 571 genera (see http://research.amnh.org/entomology/spiders/catalog/counts.html for an up-to-date list of all spider families, genera, and species).

Thus, we propose that the generic toxin name should be followed by an uppercase letter that identifies the genus of origin and a lowercase letter that identifies the species. Thus, Phoneutria nigriventer would be identified as Pn. In some cases, additional lowercase letters will be required to distinguish species that begin with the same letter. For example, Phoneutria bahiensis and Phoneutria boliviensis could be denoted Pbh and Pbv, respectively. In special cases where the species has not yet been identified, we propose use of the lowercase identifier "spp". Thus, an unidentified Phoneutria species would be given the genus/species designation Pspp.

\section{Discriminating between different toxins with the same activity and species of origin: In} some cases, distinctly different toxins (i.e., not paralogs) from the same species might have activity against the same molecular target. Examples include the $\omega$-ACTX-Hv1 and $\omega$-ACTXHv2 toxin families from $H$. versuta that both have activity against invertebrate $\mathrm{Ca}_{\mathrm{V}}$ channels (King et al., 2002), as well as the numerous different families of $\omega$-agatoxins that target vertebrate $\mathrm{Ca}_{\mathrm{V}}$ channels (Adams, 2004). In order to discriminate between these toxins, we propose that the genus/species descriptor be followed by a numerical descriptor that is simply 
incremented as new families of toxins are discovered with similar activity. Thus, if four families of $\omega$-atracotoxins had already been discovered, then the next family of toxins from these spiders with activity against $\mathrm{Ca}_{\mathrm{V}}$ channels would be denoted the $\omega$-atracotoxin-Xx5 family, where the $\mathrm{Xx}$ refers to the genus/species descriptor.

Discriminating between closely-related homologs: Spiders, cone snails, and scorpions (and probably other venomous animals) have used a combinatorial library strategy to diversify their toxin repertoire (Sollod et al., 2005) and they often express a number of closely-related homologous toxins (often referred to as isoforms) that can differ by as little as a single amino acid residue. In order to distinguish between these homologs in a manner that readily indicates their close evolutionary relationship, we propose that the numerical descriptor indicating the toxin family be followed by a lowercase letter. Thus, the six known homologs of $\omega$-ACTX-Hv1 were formerly denoted $\omega$-ACTX-Hvla through $\omega$-ACTX-Hv1f (Wang et al., 1999).

Structural information: While it would be helpful in some instances to provide information about toxin structure or even just the disulfide framework within the toxin name, this is currently very difficult because of the limited range of toxin structures that are available. For example, although there are 105 potential disulfide isomers for toxins with four disulfide bonds and 945 possible disulfide isomers for toxins with five disulfide bridges, it is unclear how many of these frameworks have been utilized by venomous animals. It seems likely that venom peptidomes include only a small number of privileged disulfide scaffolds, but the extent of these is uncertain at the present time. Thus, with the exception of the conotoxins, for which a framework definition has been developed (Terlau and Olivera, 2004), it seems premature to include structural information in the toxin name. This does not imply, however, that cysteine motifs cannot be used for toxin classification (e.g., Tytgat et al., 1999; Kozlov and Grishin, 2005). 


\subsubsection{Examples of the proposed toxin nomenclature}

Although the nomenclature we have proposed is, by design, relatively simple, it is perhaps best understood by considering several examples (summarized in Table 3).

Example 1: We first consider peptide toxins from the sea anemone genus Stichodactyla, which have previously been given trivial names such as ShK, Sh I, and gigantoxin. These names provide no information about molecular target and they disguise close evolutionary relationships, including the fact that Sh I and gigantoxin III are orthologs. We propose that all of these toxins be referred to generically as stichotoxins (SHTXs) based on the taxonomic family (Stichodactylidae) in which the genus Stichodactyla resides (see Table 2 in Supplementary Data). Thus, ShK from Stichodactyla helianthus, which is a specific blocker of $\mathrm{K}_{\mathrm{V}} 1.3$ channels, would be renamed $\kappa_{1.3^{-}}$ stichotoxin-Sh1a ( $\kappa_{1.3}$-SHTX-Sh1a) whereas Sh I, which delays $\mathrm{Na}_{\mathrm{V}}$ channel inactivation, would be re-named $\delta$-SHTX-Sh1a. Gigantoxin III, an ortholog of Sh I from S. gigantea (the two toxins are $79 \%$ identical), would be renamed $\delta$-SHTX-Sg1a, which immediately reveals its similarity to $\delta$-SHTX-Sh1a. Gigantoxin I, which has very different pharmacology to the unrelated gigantoxins II and III, would be renamed $\Omega$-SHTX-Sg1a based on its activity against the EGF receptor.

Example 2: The Brazilian armed spider Phoneutria nigriventer is one of the few spiders that are potentially deadly to humans, and hence its venom has been the subject of intensive study (reviewed in Gomez et al., 2002). Peptide toxins from this spider have typically been given trivial names such as Tx2-1, Pn2-1A, and Pn4B, mostly based on order of elution during a chromatographic separation procedure. These names have minimal information content and they disguise the fact that many of the isolated toxins, such as Tx2-1, Pn2-1A, Tx2-5, Pn2-5A, and Tx2-6, are closely related paralogs. Thus, we propose that all peptide toxins from the genus Phoneutria be described using the generic term ctenitoxin (CNTX), based on the taxonomic family (Ctenidae) in which Phoneutria resides (see Table 4 in Supplementary Data). 
Members of the Tx2-1 family of Phoneutria toxins have complex effects on $\mathrm{Na}_{\mathrm{V}}$ channels (Matavel et al., 2002) but their primary effect appears to be an inhibition of channel inactivation, a pharmacology similar to that of the $\delta$-atracotoxins (Nicholson et al., 2004) and $\delta$-conotoxins (Ekberg et al., 2007). Hence, we propose that Tx2-1 be renamed $\delta$-CNTX-Pn1a to indicate this pharmacology, and that the paralogs Tx2-5, Tx2-6, Pn2-1A and Pn2-5A be named $\delta-C N T X-P n 1 b$ through $\delta$-CNTX-Pnle, respectively. This nomenclature immediately conveys the information that these toxins are paralogs and that they have the same molecular target. In addition, using this nomenclature, the orthologous toxins PRTx32C1 and PKTx36C1 from P. reidyi and P. keyserlingi would be named $\delta$-CNTX-Pr1a and $\delta$-CNTX-Pk1a, respectively, which immediately conveys the close evolutionary relationship between this family of toxins.

Since the subtype specificity of the $\delta$-CNTXs remains to be determined, only the broad activity descriptor $(\delta)$ can be deployed at present. In contrast, Tx3-4/ $\omega$-phonetoxin-IIA and Tx3-6/PnTx36 from $P$. nigriventer appear to be specific blockers of vertebrate $\mathrm{Ca}_{\mathrm{V}} 2$ channels (Cassola et al., 1998; Dos Santos et al., 2002; Vieira et al., 2005), and consequently we propose that these toxins (which are not paralogs) be renamed $\omega_{2}$-CNTX-Pn1a and $\omega_{2}$-CNTX-Pn2a, respectively.

Example 3: Charybdotoxin ( $\alpha$-KTx 1.1) from the scorpion Leiurus quinquestriatus hebraeus is one of the most widely used peptide toxins due to its ability to specifically inhibit $\mathrm{K}_{\mathrm{Ca}}$ channels (Gimenez-Gallego et al., 1988). In addition to several homologs from L. quinquestriatus hebraeus, numerous orthologs such as iberiotoxin, BmTX2, and slotoxin have been discovered in the venom of related scorpions within the family Buthidae. These very different names disguise the evolutionary connection between these toxins and provide no information about their molecular target. We propose the generic name buthitoxin (BUTX) for all peptide toxins derived from species within Buthidae (see Table 1 in Supplementary Data). Thus, charybdotoxin would be renamed $\lambda$-BUTX-Lqh1a, where the activity descriptor $\lambda$ signifies activity against $\mathrm{K}_{\mathrm{Ca}}$ 
channels (see Table 2), and its homologs charybdotoxin b-d would be renamed $\lambda$-BUTX-Lqh1b, $\lambda$-BUTX-Lqh1c, and $\lambda$-BUTX-Lqh1d. The orthologous toxins iberiotoxin, BmTX2, and slotoxin from Hottentotta tamulus, Mesobuthus martensii, and Centruroides noxius would be renamed $\lambda$ BUTX-Mt1a, $\lambda$-BUTX-Mm1a, and $\lambda$-BUTX-Cn1a, respectively. These names make it immediately apparent that these toxins are orthologs and that they all target $\mathrm{K}_{\mathrm{Ca}}$ channels.

\section{Conclusions}

We have devised a simple, rational nomenclature for naming peptide toxins that conveys each toxin name with information about the biological origin of the peptide, its molecular target, and its relationship to known paralogs and orthologs. Although there will inevitably be some resistance to revising toxin names that have been in use for some time, it should be emphasized that systematic revision of toxin names at this point in time, with less than 1500 sequences in the Tox-Prot database, is likely to be much easier than deferring the problem to a future time when tens of thousands of peptide-toxin sequences have been determined. Moreover, the adoption of a unified nomenclature for naming peptide toxins will greatly facilitate their cataloguing and analysis using electronic databases, thus enabling their potential as drugs, insecticides, and pharmacological probes to be better exploited.

\section{Acknowledgements}

We thank Paul Alewood for comments on the manuscript, and we acknowledge financial support from the Australian Research Council (Discovery Grants DP0774245 to GFK and DP0559396 to GMN/GFK), the Australian Department of Education Science \& Technology (International Linkage Grant FR50106 to GMN/PE), and the Centre National de la Recherche Scientifique (Projets Internationaux de Coopération Scientifique Grant to PE/GMN). We dedicate this manuscript to our inspirational friend and colleague, Prof. André Ménez, who will be greatly missed. 


\section{References}

Abdel-Mottaleb, Y., Coronas, F.V., de Roodt, A.R., Possani, L.D., and Tytgat, J., 2006. A novel toxin from the venom of the scorpion Tityus trivittatus, is the first member of a new $\alpha-K T X$ subfamily. FEBS Lett 580, 592-596.

Adams, M.E., Myers, R.A., Imperial, J.S., and Olivera, B.M., 1993. Toxityping rat brain calcium channels with $\omega$-toxins from spider and cone snail venoms. Biochemistry 32, 12566-12570.

Adams, M.E., 2004. Agatoxins: ion channel specific toxins from the American funnel web spider, Agelenopsis aperta. Toxicon 43, 509-525.

Alexander, S.P.H., Mathie, A., and Peters, J.A., 2007. Guide to receptors and channels, 2nd edition (2007 Revision). Br. J. Pharmacol. 150 (Suppl. 1), S1-S168.

Ambar, I., Kloog, Y., Kochva, E., Wollberg, Z., Bdolah, A., Oron, U., and Sokolovsky, M., 1988. Characterization and localization of a novel neuroreceptor for the peptide sarafotoxin. Biochem. Biophys. Res. Commun. 157, 1104-1110.

Anderluh, G., and Macek, P., 2002. Cytolytic peptide and protein toxins from sea anemones (Anthozoa: Actiniaria). Toxicon 40, 111-124.

Armishaw, C.J., Daly, N.L., Nevin, S.T., Adams, D.J., Craik, D.J., and Alewood, P.F., 2006. aSelenoconotoxins, a new class of potent $\alpha_{7}$ neuronal nicotinic receptor antagonists. J. Biol. Chem. 281, 14136-14143.

Bindokas, V.P., and Adams, M.E., 1989. w-Aga-I: a presynaptic calcium channel antagonist from venom of the funnel web spider, Agelenopsis aperta. J. Neurobiol. 20, 171-188.

Boeckmann, B., Bairoch, A., Apweiler, R., Blatter, M.C., Estreicher, A., Gasteiger, E., Martin, M.J., Michoud, K., O'Donovan, C., Phan, I., Pilbout, S., and Schneider, M., 2003. The SWISS-PROT protein knowledgebase and its supplement TrEMBL in 2003. Nucleic Acids Res. 31, 365-370.

Bosmans, F., and Tytgat, J., 2007. Sea anemone venom as a source of insecticidal peptides acting on voltage-gated $\mathrm{Na}^{+}$channels. Toxicon 49, 550-560.

Brown, M.R., Sheumack, D.D., Tyler, M.I., and Howden, M.E.H., 1988. Amino acid sequence of versutoxin, a lethal neurotoxin from the venom of the funnel-web spider Atrax versutus. Biochem. J. 250, 401-405.

Brown, R.L., Haley, T.L., West, K.A., and Crabb, J.W., 1999. Pseudechetoxin: a peptide blocker of cyclic nucleotide-gated ion channels. Proc. Natl. Acad. Sci. USA 96, 754-759.

Buczek, O., Wei, D., Babon, J.J., Yang, X., Fiedler, B., Chen, P., Yoshikami, D., Olivera, B.M., Bulaj, G., and Norton, R.S., 2007. Structure and sodium channel activity of an excitatory $\mathrm{I}_{1}$-superfamily conotoxin. Biochemistry 46, 9929-9940.

Cassola, A.C., Jaffe, H., Fales, H.M., Afeche, S.C., Magnoli, F., and Cipolla-Neto, J., 1998. w-phonetoxinIIA: a calcium channel blocker from the spider Phoneutria nigriventer. Pflugers Arch 436, 545-552.

Castaneda, O., Sotolongo, V., Amor, A.M., Stocklin, R., Anderson, A.J., Harvey, A.L., Engstrom, A., Wernstedt, C., and Karlsson, E., 1995. Characterization of a potassium channel toxin from the Caribbean sea anemone Stichodactyla helianthus. Toxicon 33, 603-613.

Changeux, J.P., Kasai, M., and Lee, C.Y., 1970. Use of a snake venom toxin to characterize the cholinergic receptor protein. Proc. Natl. Acad. Sci. USA 67, 1241-1247.

Clark, R.J., Fischer, H., Dempster, L., Daly, N.L., Rosengren, K.J., Nevin, S.T., Meunier, F.A., Adams, D.J., and Craik, D.J., 2005. Engineering stable peptide toxins by means of backbone cyclization: stabilization of the $\alpha$-conotoxin MII. Proc. Natl. Acad. Sci. USA 102, 13767-13772.

Cohen, L., Karbat, I., Gilles, N., Froy, O., Corzo, G., Angelovici, R., Gordon, D., and Gurevitz, M., 2004. Dissection of the functional surface of an anti-insect excitatory toxin illuminates a putative "hot spot" common to all scorpion $\beta$-toxins affecting $\mathrm{Na}^{+}$channels. J. Biol. Chem. 279, 8206-8211.

Cordeiro, M.N., Diniz, C.R., Valentim, A.C., von Eickstedt, V.R., Gilroy, J., and Richardson, M., 1992. The purification and amino acid sequences of four Tx2 neurotoxins from the venom of the Brazilian 'armed' spider Phoneutria nigriventer (Keys). FEBS Lett. 310, 153-156.

Cordeiro, M.N., de Figueiredo, S.G., Valentim, A.C., Diniz, C.R., von Eickstedt, V.R., Gilroy, J., and Richardson, M., 1993. Purification and amino acid sequences of six Tx3 type neurotoxins from the venom of the Brazilian 'armed' spider Phoneutria nigriventer (Keys). Toxicon 31, 35-42. 
Craig, A.G., Norberg, T., Griffin, D., Hoeger, C., Akhtar, M., Schmidt, K., Low, W., Dykert, J., Richelson, E., Navarro, V., Mazella, J., Watkins, M., Hillyard, D., Imperial, J., Cruz, L.J., and Olivera, B.M., 1999. Contulakin-G, an O-glycosylated invertebrate neurotensin. J. Biol. Chem. 274, 13752-13759.

Cruz, L.J., de Santos, V., Zafaralla, G.C., Ramilo, C.A., Zeikus, R., Gray, W.R., and Olivera, B.M., 1987. Invertebrate vasopressin/oxytocin homologs. Characterization of peptides from Conus geographus and Conus straitus venoms. J. Biol. Chem. 262, 15821-15824.

de Figueiredo, S.G., Garcia, M.E., Valentim, A.C., Cordeiro, M.N., Diniz, C.R., and Richardson, M., 1995. Purification and amino acid sequence of the insecticidal neurotoxin Tx4(6-1) from the venom of the "armed" spider Phoneutria nigriventer (Keys). Toxicon 33, 83-93.

Deakins, D.E., and Saunders, P.R., 1967. Purification of the lethal fraction of the venom of the stonefish Synanceja horrida (Linnaeus). Toxicon 4, 257-262.

Diochot, S., Baron, A., Rash, L.D., Deval, E., Escoubas, P., Scarzello, S., Salinas, M., and Lazdunski, M., 2004. A new sea anemone peptide, APETx2, inhibits ASIC3, a major acid-sensitive channel in sensory neurons. EMBO J. 23, 1516-1525.

Dos Santos, R.G., Van Renterghem, C., Martin-Moutot, N., Mansuelle, P., Cordeiro, M.N., Diniz, C.R., Mori, Y., De Lima, M.E., and Seagar, M., 2002. Phoneutria nigriventer $\omega$-phonetoxin IIA blocks the $\mathrm{Ca}_{\mathrm{v}} 2$ family of calcium channels and interacts with $\omega$-conotoxin-binding sites. J. Biol. Chem. 277, 13856-13862.

Ekberg, J., Craik, D.J., and Adams, D.J., 2007. Conotoxin modulation of voltage-gated sodium channels. Int. J. Biochem. Cell Biol., in press (doi:10.1016/j.biocel.2007.08.017).

England, L.J., Imperial, J., Jacobsen, R., Craig, A.G., Gulyas, J., Akhtar, M., Rivier, J., Julius, D., and Olivera, B.M., 1998. Inactivation of a serotonin-gated ion channel by a polypeptide toxin from marine snails. Science 281, 575-578.

Escoubas, P., De Weille, J.R., Lecoq, A., Diochot, S., Waldmann, R., Champigny, G., Moinier, D., Menez, A., and Lazdunski, M., 2000. Isolation of a tarantula toxin specific for a class of proton-gated $\mathrm{Na}^{+}$ channels. J. Biol. Chem. 275, 25116-25121.

Escoubas, P., and Rash, L., 2004. Tarantulas: eight-legged pharmacists and combinatorial chemists. Toxicon 43, 555-574.

Escoubas, P., 2006. Mass spectrometry in toxinology: a 21st-century technology for the study of biopolymers from venoms. Toxicon 47, 609-613.

Escoubas, P., Sollod, B.L., and King, G.F., 2006. Venom landscapes: mining the complexity of spider venoms via a combined cDNA and mass spectrometric approach. Toxicon 47, 650-663.

Escoubas, P., Quinton, L., and Nicholson, G.M., 2008. Venomics: unravelling the complexity of animal venoms with mass spectrometry. J. Mass. Spectrom. Rev. 43, 279-295.

Fainzilber, M., Nakamura, T., Lodder, J.C., Zlotkin, E., Kits, K.S., and Burlingame, A.L., 1998. YConotoxin-PnVIIA, a $y$-carboxyglutamate-containing peptide agonist of neuronal pacemaker cation currents. Biochemistry 37, 1470-1477.

Fajloun, Z., Kharrat, R., Chen, L., Lecomte, C., Di Luccio, E., Bichet, D., El Ayeb, M., Rochat, H., Allen, P.D., Pessah, I.N., De Waard, M., and Sabatier, J.M., 2000. Chemical synthesis and characterization of maurocalcine, a scorpion toxin that activates $\mathrm{Ca}^{2+}$ release channel/ryanodine receptors. FEBS Lett. 469, 179-185.

Favreau, P., Menin, L., Michalet, S., Perret, F., Cheneval, O., Stöcklin, M., Bulet, P., and Stöcklin, R., 2006. Mass spectrometry strategies for venom mapping and peptide sequencing from crude venoms: case applications with single arthropod specimen. Toxicon 47, 676-687.

Fet, V., and Soleglad, M.E., 2005. Contributions to scorpion systematics. I. On recent changes in highlevel taxonomy. Euscorpius 31, 1-13.

Fletcher, J.I., Chapman, B.E., Mackay, J.P., Howden, M.E.H., and King, G.F., 1997a. The structure of versutoxin ( $\delta$-atracotoxin-Hv1) provides insights into the binding of site 3 neurotoxins to the voltagegated sodium channel. Structure 5, 1525-1535.

Fletcher, J.I., Smith, R., O'Donoghue, S.I., Nilges, M., Connor, M., Howden, M.E.H., Christie, M.J., and King, G.F., 1997b. The structure of a novel insecticidal neurotoxin, $\omega$-atracotoxin-HV1, from the venom of an Australian funnel web spider. Nat. Struct. Biol. 4, 559-566.

Froy, O., Sagiv, T., Poreh, M., Urbach, D., Zilberberg, N., and Gurevitz, M., 1999a. Dynamic diversification from a putative common ancestor of scorpion toxins affecting sodium, potassium, and chloride channels. J. Mol. Evol. 48, 187-196. 
Froy, O., Zilberberg, N., Gordon, D., Turkov, M., Gilles, N., Stankiewicz, M., Pelhate, M., Loret, E., Oren, D.A., Shaanan, B., and Gurevitz, M., 1999b. The putative bioactive surface of insect-selective scorpion excitatory neurotoxins. J. Biol. Chem. 274, 5769-5776.

Fry, B.G., Vidal, N., Norman, J.A., Vonk, F.J., Scheib, H., Ramjan, S.F.R., Kuruppu, S., Fung, K., Hedges, S.B., Richardson, M.K., Hodgson, W.C., Ignjatovic, V., Summerhayes, R., and Kochva, E., 2006. Early evolution of the venom system in lizards and snakes. Nature 439, 584-588.

Fuller, M.D., Thompson, C.H., Zhang, Z.R., Freeman, C.S., Schay, E., Szakacs, G., Bakos, E., Sarkadi, B., McMaster, D., French, R.J., Pohl, J., Kubanek, J., and McCarty, N.A., 2007. State-dependent Inhibition of cystic fibrosis transmembrane conductance regulator chloride channels by a novel peptide toxin. J. Biol. Chem. 282, 37545-37555.

Galvez, A., Gimenez-Gallego, G., Reuben, J.P., Roy-Contancin, L., Feigenbaum, P., Kaczorowski, G.J., and Garcia, M.L., 1990. Purification and characterization of a unique, potent, peptidyl probe for the high conductance calcium-activated potassium channel from venom of the scorpion Buthus tamulus. J. Biol. Chem. 265, 11083-118090.

Garcia-Valdes, J., Zamudio, F.Z., Toro, L., and Possani, L.D., 2001. Slotoxin, $\alpha$ KTx1.11, a new scorpion peptide blocker of MaxiK channels that differentiates between $\alpha$ and $\alpha+\beta$ ( $\beta 1$ or $\beta 4$ ) complexes. FEBS Lett. 505, 369-373.

Gimenez-Gallego, G., Navia, M.A., Reuben, J.P., Katz, G.M., Kaczorowski, G.J., and Garcia, M.L., 1988. Purification, sequence, and model structure of charybdotoxin, a potent selective inhibitor of calciumactivated potassium channels. Proc. Natl. Acad. Sci. USA 85, 3329-3333.

Gomez, M.V., Kalapothakis, E., Guatimosim, C., and Prado, M.A.M., 2002. Phoneutria nigriventer venom: a cocktail of toxins that affect ion channels. Cell. Mol. Neurobiol. 22, 579-588.

Gray, M.R., 1988. Aspects of the systematics of the Australian funnel web spiders (Araneae: Hexathelidae: Atracinae) based upon morphological and electrophoretic data. In: Austin, A.D. and Heather, N.W. (Eds), Australian arachnology, The Australian Entomological Society, Brisbane, pp. 113125.

Gray, W.R., Luque, A., Olivera, B.M., Barrett, J., and Cruz, L.J., 1981. Peptide toxins from Conus geographus venom. J. Biol. Chem. 256, 4734-4740.

Gunning, S.J., Chong, Y., Khalife, A.A., Hains, P.G., Broady, K.W., and Nicholson, G.M., 2003. Isolation of $\delta$-missulenatoxin-Mb1a, the major vertebrate-active spider $\delta$-toxin from the venom of Missulena bradleyi (Actinopodidae). FEBS Lett 554, 211-218.

Haas, Q., Westermann, J.C., Halai, R., Wang, C.K.L., and Craik, D.J., 2008. ConoServer, a database for conopeptide sequences and structures. Bioinformatics 24, 445-446.

Harvey, A.L., 2002. Toxins 'R' Us: more pharmacological tools from nature's superstore. Trends Pharmacol. Sci. 23, 201-203.

Jin, W., and Lu, Z., 1998. A novel high-affinity inhibitor for inward-rectifier $\mathrm{K}^{+}$channels. Biochemistry 37 , 13291-13299.

Jungo, F., and Bairoch, A., 2005. Tox-Prot, the toxin protein annotation program of the Swiss-Prot protein knowledgebase. Toxicon 45, 293-301.

Kalapothakis, E., Penaforte, C.L., Beirão, P.S.L., Romano-Silva, M.A., Cruz, J.S., Prado, M.A.M., Guimarães, P.E.M., Gomez, M.V., and Prado, V.F., 1998. Cloning of cDNAs encoding neurotoxic peptides from the spider Phoneutria nigriventer. Toxicon 36, 1843-1850.

King, G.F., Tedford, H.W., and Maggio, F., 2002. Structure and function of insecticidal neurotoxins from Australian funnel-web spiders. J. Toxicol.-Toxin Rev. 21, 359-389.

King, G.F., 2007. Modulation of insect $\mathrm{Ca}_{v}$ channels by peptidic spider toxins. Toxicon 49, 513-530.

King, G.F., Escoubas, P., and Nicholson, G.M., 2008. Peptide toxins that selectively target insect $\mathrm{Na}_{v}$ and $\mathrm{Ca}_{V}$ channels. Channels, in press.

Kozlov, S., and Grishin, E., 2005. Classification of spider neurotoxins using structural motifs by primary structure features. Single residue distribution analysis and pattern analysis techniques. Toxicon 46, 672-686.

Kozlov, S., Malyavka, A., McCutchen, B., Lu, A., Schepers, E., Herrmann, R., and Grishin, E., 2005. A novel strategy for the identification of toxinlike structures in spider venom. Proteins 59, 131-140.

Kuhn-Nentwig, L., 2003. Antimicrobial and cytolytic peptides of venomous arthropods. Cell. Mol. Life Sci. 60, 2651-2658. 
Kuhn-Nentwig, L., Schaller, J., and Nentwig, W., 2004. Biochemistry, toxicology and ecology of the venom of the spider Cupiennius salei (Ctenidae). Toxicon 43, 543-553.

Lewis, R.J., and Garcia, M.L., 2003. Therapeutic potential of venom peptides. Nat. Rev. Drug Discov. 2, 790-802.

Lu, Z., and MacKinnon, R., 1997. Purification, characterization, and synthesis of an inward-rectifier $\mathrm{K}^{+}$ channel inhibitor from scorpion venom. Biochemistry 36, 6936-6940.

Lucchesi, K., Ravindran, A., Young, H., and Moczydlowski, E., 1989. Analysis of the blocking activity of charybdotoxin homologs and iodinated derivatives against $\mathrm{Ca}^{2+}$-activated $\mathrm{K}^{+}$channels. J. Membr. Biol. 109, 269-281.

Maggio, F., and King, G.F., 2002. Scanning mutagenesis of a Janus-faced atracotoxin reveals a bipartite surface patch that is essential for neurotoxic function. J. Biol. Chem. 277, 22806-22813.

Marshall, D.L., Vatanpour, H., Harvey, A.L., Boyot, P., Pinkasfeld, S., Doljansky, Y., Bouet, F., and Ménez, A., 1994. Neuromuscular effects of some potassium channel blocking toxins from the venom of the scorpion Leiurus quinquestriatus hebreus. Toxicon 32, 1433-1443.

Matavel, A., Cruz, J.S., Penaforte, C.L., Araujo, D.A., Kalapothakis, E., Prado, V.F., Diniz, C.R., Cordeiro, M.N., and Beirao, P.S., 2002. Electrophysiological characterization and molecular identification of the Phoneutria nigriventer peptide toxin PnTx2-6. FEBS Lett. 523, 219-223.

Mclntosh, J.M., Olivera, B.M., and Cruz, L.J., 1999a. Conus peptides as probes for ion channels. Methods Enzymol. 294, 605-624.

McIntosh, J.M., Santos, A.D., and Olivera, B.M., 1999b. Conus peptides targeted to specific nicotinic acetylcholine receptor subtypes. Annu. Rev. Biochem. 68, 59-88.

Meier, J., and Stocker, K., 1992. Towards a nomenclature system of animal, plant and microbial toxins. Toxicon 30, 681-684.

Mena, E.E., Gullak, M.F., Pagnozzi, M.J., Richter, K.E., Rivier, J., Cruz, L.J., and Olivera, B.M., 1990. Conantokin-G: a novel peptide antagonist to the $\mathrm{N}$-methyl-D-aspartic acid (NMDA) receptor. Neurosci. Lett. 118, 241-244.

Menez, A., Stocklin, R., and Mebs, D., 2006. 'Venomics' or: The venomous systems genome project. Toxicon 47, 255-259.

Miller, C., Moczydlowski, E., Latorre, R., and Phillips, M., 1985. Charybdotoxin, a protein inhibitor of single $\mathrm{Ca}^{2+}$-activated $\mathrm{K}^{+}$channels from mammalian skeletal muscle. Nature $313,316-318$.

Miller, C., 1995. The charybdotoxin family of $\mathrm{K}^{+}$channel-blocking peptides. Neuron $15,5-10$.

Mintz, I.M., Venema, V.J., Swiderek, K.M., Lee, T.D., Bean, B.P., and Adams, M.E., 1992. P-type calcium channels blocked by the spider toxin $\omega$-Aga-IVA. Nature 355, 827-829.

Nicholson, G.M., Willow, M., Howden, M.E.H., and Narahashi, T., 1994. Modification of sodium channel gating and kinetics by versutoxin from the Australian funnel-web spider Hadronyche versuta. Pflügers Arch. (Eur. J. Physiol.) 428, 400-409.

Nicholson, G.M., Walsh, R., Little, M.J., and Tyler, M.I., 1998. Characterisation of the effects of robustoxin, the lethal neurotoxin from the Sydney funnel-web spider Atrax robustus, on sodium channel activation and inactivation. Pflügers Arch. (Eur. J. Physiol.) 436, 117-126.

Nicholson, G.M., Little, M.J., and Birinyi-Strachan, L.C., 2004. Structure and function of $\delta$-atracotoxins: lethal neurotoxins targeting the voltage-gated sodium channel. Toxicon 43, 587-599.

Norton, R.S., 1991. Structure and structure-function relationships of sea anemone proteins that interact with the sodium channel. Toxicon 29, 1051-1084.

Norton, R.S., and Olivera, B.M., 2006. Conotoxins down under. Toxicon 48, 780-798.

Olivera, B.M., 1997. E.E. Just Lecture, 1996. Conus venom peptides, receptor and ion channel targets, and drug design: 50 million years of neuropharmacology. Mol. Biol. Cell. 8, 101-109.

Olivera, B.M., and Cruz, L.J., 2001. Conotoxins, in retrospect. Toxicon 39, 7-14.

Olivera, B.M., 2002. Conus venom peptides: reflections from the biology of clades and species. Annu. Rev. Ecol. Syst. 33, 25-47.

Pallaghy, P.K., Alewood, D., Alewood, P.F., and Norton, R.S., 1997. Solution structure of robustoxin, the lethal neurotoxin from the funnel-web spider Atrax robustus. FEBS Lett. 419, 191-196.

Platnick, N.I., 1997. Advances in spider taxonomy, 1992-1995: with redescriptions 1940-1980 (updated online version available at http://research.amnh.org/entomology/spiders/catalog81-87). New York Entomological Society \& The American Museum of Natural History, New York. 
Possani, L.D., Becerril, B., Delepierre, M., and Tytgat, J., 1999. Scorpion toxins specific for $\mathrm{Na}^{+}$-channels. Eur. J. Biochem. 264, 287-300.

Possani, L.D., Merino, E., Corona, M., Bolivar, F., and Becerril, B., 2000. Peptides and genes coding for scorpion toxins that affect ion-channels. Biochimie 82, 861-868.

Prendini, L., and Wheeler, W.C., 2005. Scorpion higher phylogeny and classification, taxonomic anarchy, and standards for peer review in online publishing. Cladistics 21, 446-494.

Putnam, N.H., Srivastava, M., Hellsten, U., Dirks, B., Chapman, J., Salamov, A., Terry, A., Shapiro, H., Lindquist, E., Kapitonov, V.V., Jurka, J., Genikhovich, G., Grigoriev, I.V., Lucas, S.M., Steele, R.E., Finnerty, J.R., Technau, U., Martindale, M.Q., and Rokhsar, D.S., 2007. Sea anemone genome reveals ancestral eumetazoan gene repertoire and genomic organization. Science 317, 86-94.

Rodriguez de la Vega, R.C., and Possani, L.D., 2004. Current views on scorpion toxins specific for $\mathrm{K}^{+}-$ channels. Toxicon 43, 865-875.

Romi-Lebrun, R., Lebrun, B., Martin-Eauclaire, M.F., Ishiguro, M., Escoubas, P., Wu, F.Q., Hisada, M., Pongs, O., and Nakajima, T., 1997. Purification, characterization, and synthesis of three novel toxins from the Chinese scorpion Buthus martensi, which act on $\mathrm{K}^{+}$channels. Biochemistry 36, 13473-13482.

Satake, H., Villegas, E., Oshiro, N., Terada, K., Shinada, T., and Corzo, G., 2004. Rapid and efficient identification of cysteine-rich peptides by random screening of a venom gland cDNA library from the hexathelid spider Macrothele gigas. Toxicon 44, 149-156.

Sato, S., Yoshida, H., Abe, H., and Tamiya, N., 1969. Properties and biosynthesis of a neurotoxic protein of the venoms of s snakes Laticauda laticaudata and Laticauda colubrina. Biochem. J. 115, 85-90.

Sharpe, I.A., Gehrmann, J., Loughnan, M.L., Thomas, L., Adams, D.A., Atkins, A., Palant, E., Craik, D.J., Adams, D.J., Alewood, P.F., and Lewis, R.J., 2001. Two new classes of conopeptides inhibit the a1adrenoceptor and noradrenaline transporter. Nat. Neurosci. 4, 902-907.

Sheumack, D.D., Claassens, R., Howden, M.E.H., and Whitley, N.M., 1985. Complete amino acid sequence of of a new type of lethal neurotoxin from the venom of the funnel-web spider Atrax robustus. FEBS Lett. 181, 154-156.

Shiomi, K., Honma, T., Ide, M., Nagashima, Y., Ishida, M., and Chino, M., 2003. An epidermal growth factor-like toxin and two sodium channel toxins from the sea anemone Stichodactyla gigantea. Toxicon 41, 229-236.

Shon, K.J., Grilley, M., Jacobsen, R., Cartier, G.E., Hopkins, C., Gray, W.R., Watkins, M., Hillyard, D.R., Rivier, J., Torres, J., Yoshikami, D., and Olivera, B.M., 1997. A noncompetitive peptide inhibitor of the nicotinic acetylcholine receptor from Conus purpurascens venom. Biochemistry 36, 9581-9587.

Siemens, J., Zhou, S., Piskorowski, R., Nikai, T., Lumpkin, E.A., Basbaum, A.I., King, D., and Julius, D., 2006. Spider toxins activate the capsaicin receptor to produce inflammatory pain. Nature 444, 208-212.

Skinner, W.S., Adams, M.E., Quistad, G.B., Kataoka, H., Cesarin, B.J., Enderlin, F.E., and Schooley, D.A., 1989. Purification and characterization of two classes of neurotoxins from the funnel web spider, Agelenopsis aperta. J. Biol. Chem. 264, 2150-2155.

Sollod, B.L., Wilson, D., Zhaxybayeva, O., Gogarten, J.P., Drinkwater, R., and King, G.F., 2005. Were arachnids the first to use combinatorial peptide libraries? Peptides 26, 131-139.

Sutton, K.G., Siok, C., Stea, A., Zamponi, G.W., Heck, S.D., Volkmann, R.A., Ahlijanian, M.K., and Snutch, T.P., 1998. Inhibition of neuronal calcium channels by a novel peptide spider toxin, DW13.3. Mol. Pharmacol. 54, 407-418.

Szeto, T.H., Wang, X.-H., Smith, R., Connor, M., Christie, G.M., Nicholson, G.M., and King, G.F., 2000. Isolation of a funnel-web spider polypeptide with homology to mamba intestinal toxin 1 and the embryonic head inducer Dickkopf-1. Toxicon 38, 429-442.

Tan, P.T., Veeramani, A., Srinivasan, K.N., Ranganathan, S., and Brusic, V., 2006. SCORPION2: a database for structure-function analysis of scorpion toxins. Toxicon 47, 356-363.

Tedford, H.W., Gilles, N., Ménez, A., Doering, C.J., Zamponi, G.W., and King, G.F., 2004a. Scanning mutagenesis of $\omega$-atracotoxin-Hv1a reveals a spatially restricted epitope that confers selective activity against invertebrate calcium channels. J. Biol. Chem. 279, 44133-44140.

Tedford, H.W., Sollod, B.L., Maggio, F., and King, G.F., 2004b. Australian funnel-web spiders: master insecticide chemists. Toxicon 43, 601-618.

Terlau, H., Shon, K.J., Grilley, M., Stocker, M., Stuhmer, W., and Olivera, B.M., 1996. Strategy for rapid immobilization of prey by a fish-hunting marine snail. Nature 381, 148-151. 
Terlau, H., and Olivera, B.M., 2004. Conus venoms: a rich source of novel ion channel-targeted peptides. Physiol. Rev. 84, 41-68.

Tytgat, J., Chandy, K.G., Garcia, M.L., Gutman, G.A., Martin-Eauclaire, M.F., van der Walt, J.J., and Possani, L.D., 1999. A unified nomenclature for short-chain peptides isolated from scorpion venoms: $\alpha$ KTx molecular subfamilies. Trends Pharmacol. Sci. 20, 444-447.

Tzeng, M.C., and Siekevitz, P., 1978. The effect of the purified major protein factor ( $\alpha$-latrotoxin) of black widow spider venom on the release of acetylcholine and norepinephrine from mouse cerebral cortex slices. Brain Res. 139, 190-196.

Vieira, L.B., Kushmerick, C., Hildebrand, M.E., Garcia, E., Stea, A., Cordeiro, M.N., Richardson, M., Gomez, M.V., and Snutch, T.P., 2005. Inhibition of high voltage-activated calcium channels by spider toxin PnTx3-6. J. Pharmacol. Exp. Ther. 314, 1370-1377.

Wang, X.-H., Smith, R., Fletcher, J.I., Wilson, H., Wood, C.J., Howden, M.E.H., and King, G.F., 1999. Structure-function studies of $\omega$-atracotoxin, a potent antagonist of insect voltage-gated calcium channels. Eur. J. Biochem. 264, 488-494.

Wang, X.-H., Connor, M., Wilson, D., Wilson, H.I., Nicholson, G.M., Smith, R., Shaw, D., Mackay, J.P., Alewood, P.F., Christie, M.J., and King, G.F., 2001. Discovery and structure of a potent and highly specific blocker of insect calcium channels. J. Biol. Chem. 276, 40806-40812.

Whysner, J.A., and Saunders, P.R., 1966. Purification of the lethal fraction of the venom of the marine snail Conus californicus. Toxicon 4, 177-181.

Yan, L., and Adams, M.E., 1998. Lycotoxins, antimicrobial peptides from venom of the wolf spider Lycosa carolinensis. J. Biol. Chem. 273, 2059-2066. 


\section{Figure legends}

Figure 1: Cumulative total number of peptide toxin sequences reported for (A) scorpions, (B) spiders, (C) sea anemones, (D) marine cone snails, and (E) snakes for the period 1967-2006. The Tox-Prot database (Jungo and Bairoch, 2005) was used to determine the year in which a particular peptide sequence was first published, patented, or submitted to the Swiss-Prot database. Fragments and incomplete sequences were excluded from the analysis. (F) The data shown in panels (A)-(D) were used to determine the combined total number of peptide toxin sequences discovered from anemones, cone snails, scorpions, and spiders during the period 1967-2006.

Figure 2: Exponential fit (solid line) to the cumulative total number of peptide toxin sequences discovered from anemones, cone snails, scorpions, and spiders during the period 1985-2006. Extrapolation of the fitted curve (dotted line) yields projections for the total number of peptidetoxin sequences likely to be deposited in electronic databases in future years. Note the log scale on the ordinate axis.

Figure 3: Schematic of the proposed nomenclature for naming peptide toxins. The toxin name can be broadly divided into three parts that describe the toxin's activity (blue), biological source (red), and relationship to other toxins (green/purple). The example given is for a sea anemone toxin, commonly known as $\mathrm{ShK}$, that specifically targets $\mathrm{K}_{\mathrm{V}} 1.3$ channels. The subtype descriptor should be based on IUPHAR-recommended nomenclature for channels and receptors (Alexander et al., 2007).

Figure 4: Alignment of the primary structure of orthologous peptide toxins from the spiders Hadronyche versuta ( $\delta$-ACTX-Hv1a) and Macrothele gigas (Magi-14), along with revised names based on the nomenclature proposed herein. Identical residues are shaded grey. 
Table 1: Estimated number of unique peptide toxins in venomous animals

\begin{tabular}{|c|c|c|}
\hline Animal Group & No. of Peptides & References \\
\hline Cone snails & 50,000 & $\begin{array}{l}\text { (Olivera and Cruz, 2001; Norton and Olivera, } \\
\text { 2006) }\end{array}$ \\
\hline Scorpions & 100,000 & (Possani et al., 1999) \\
\hline Spiders & $1.5-16$ million & $\begin{array}{l}\text { (Escoubas and Rash, 2004; Tedford et al., 2004b; } \\
\text { Escoubas et al., 2006) }\end{array}$ \\
\hline
\end{tabular}




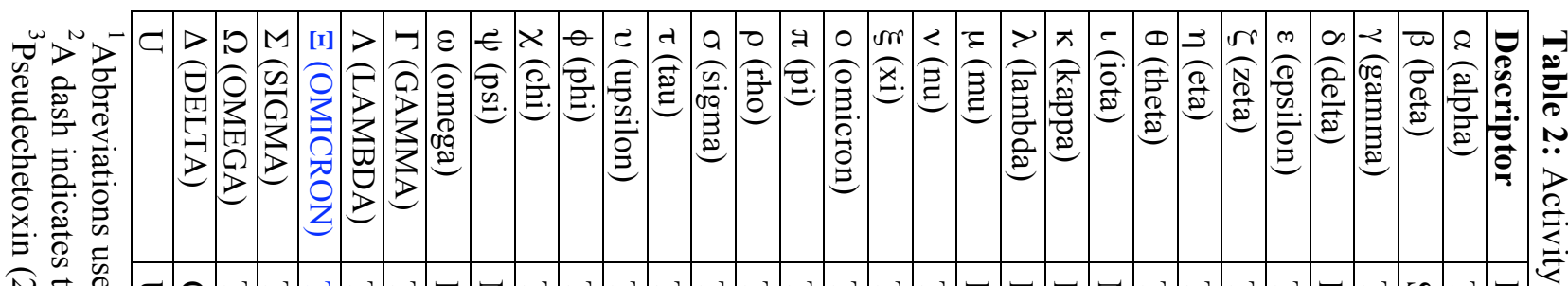

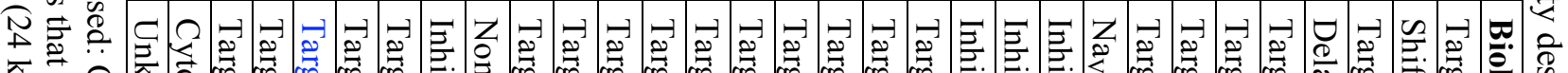

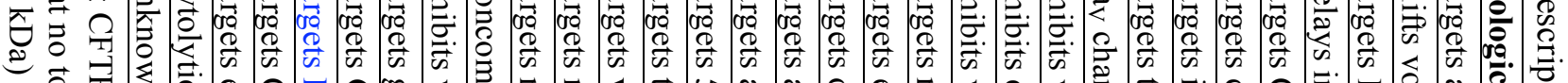

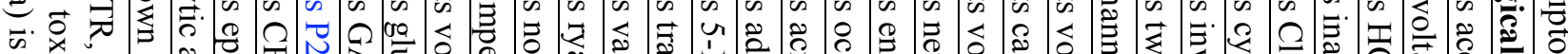

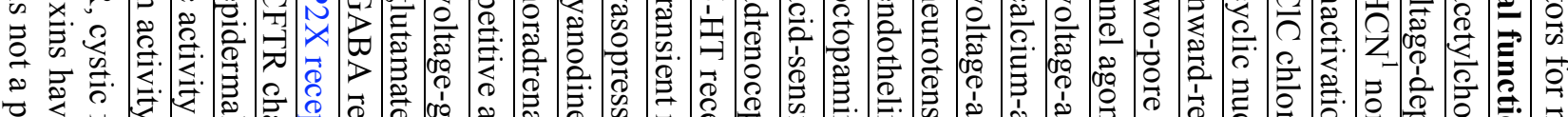

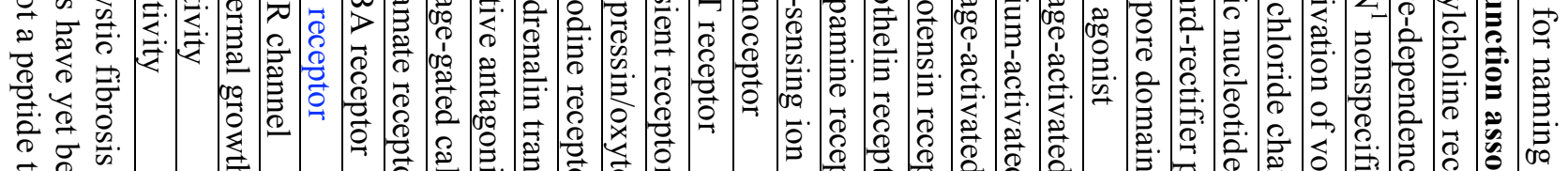

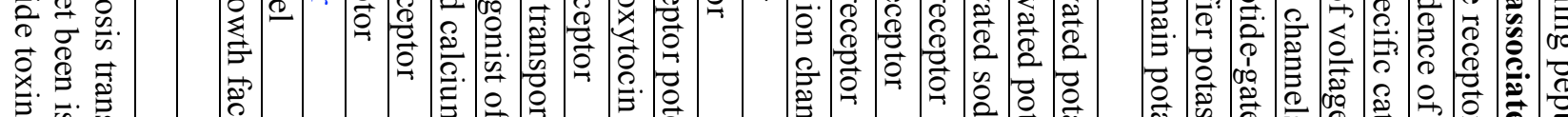

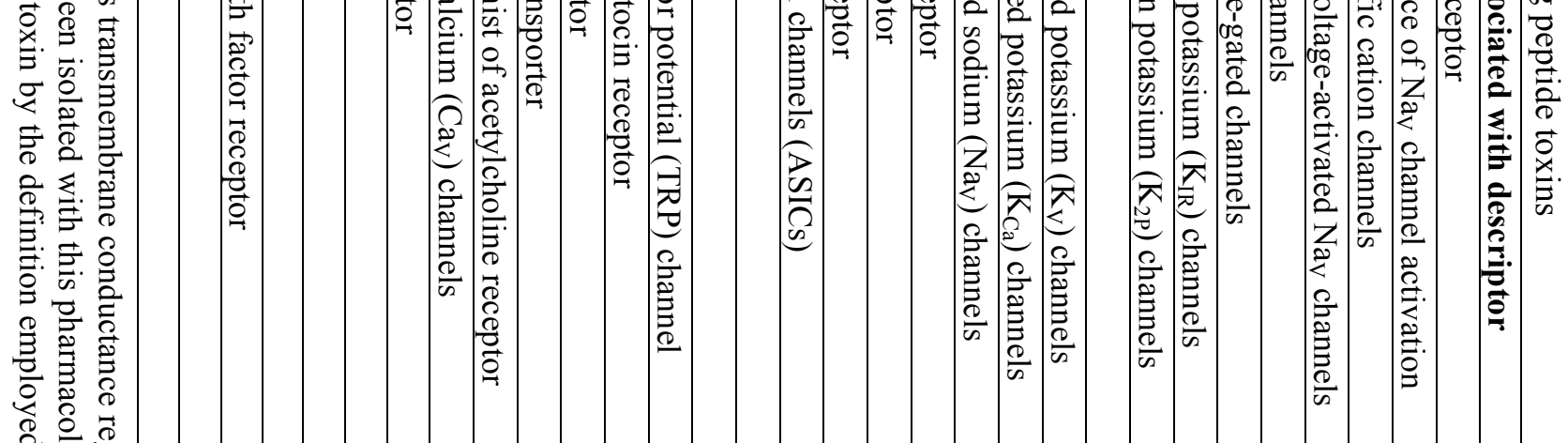

o 0

항

के

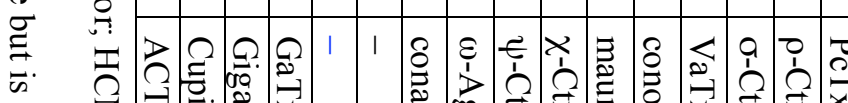

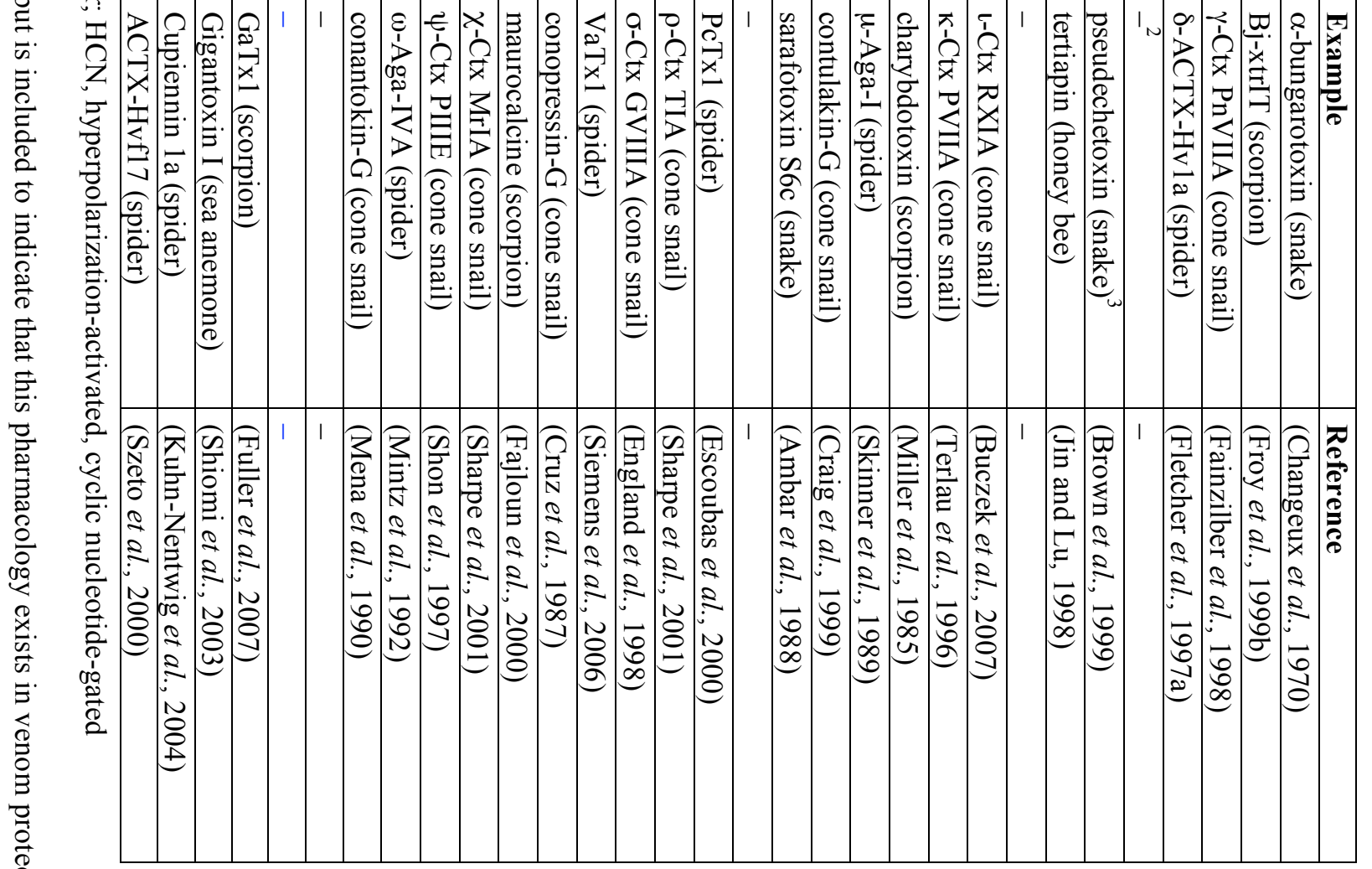



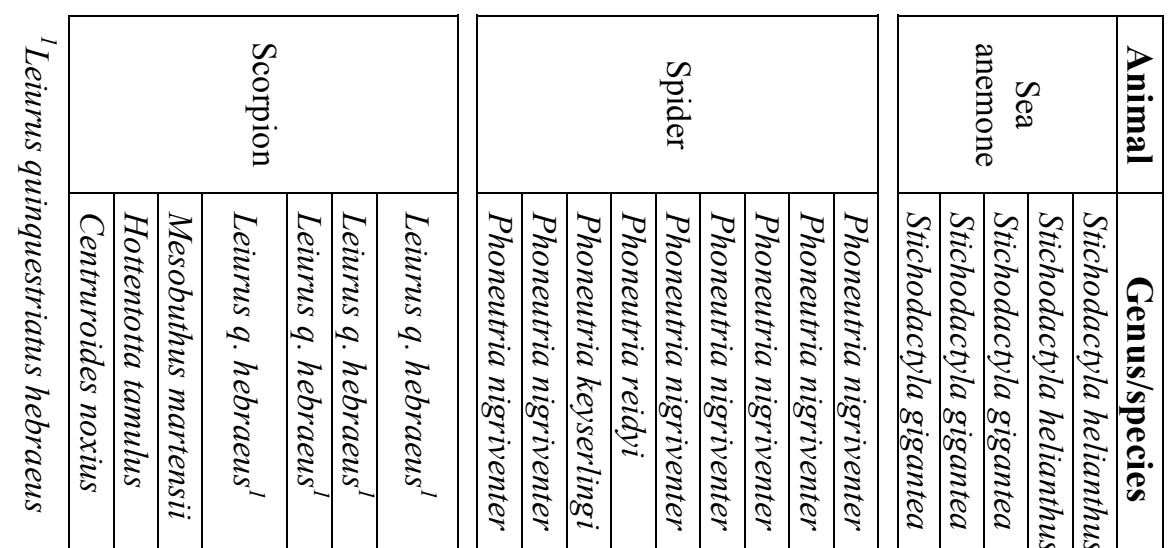

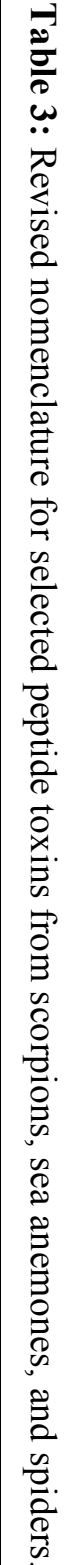

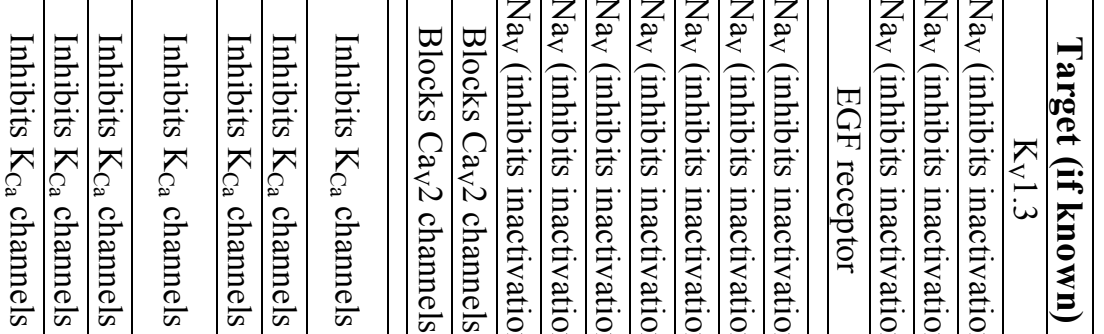

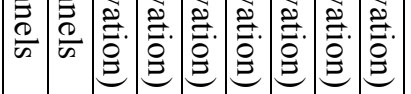

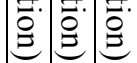

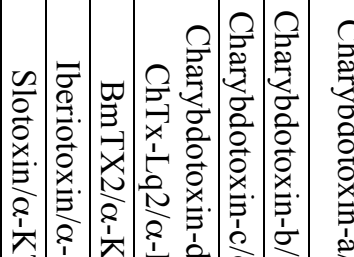

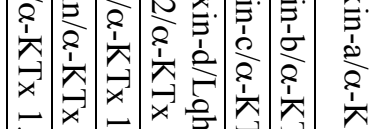

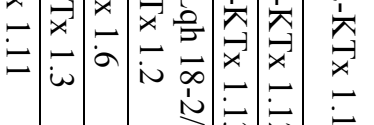

$\underset{x}{*}$

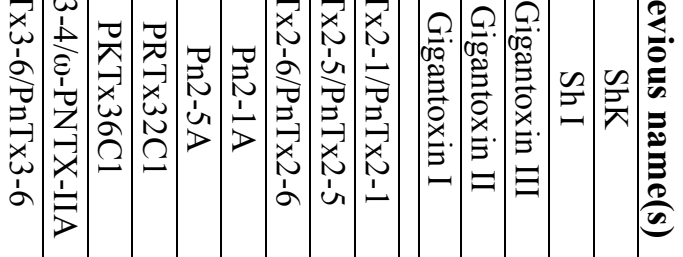

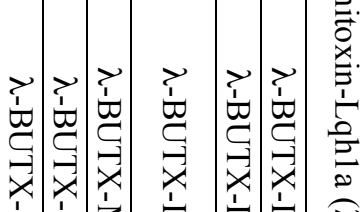
气ُ̂

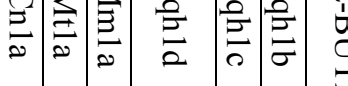

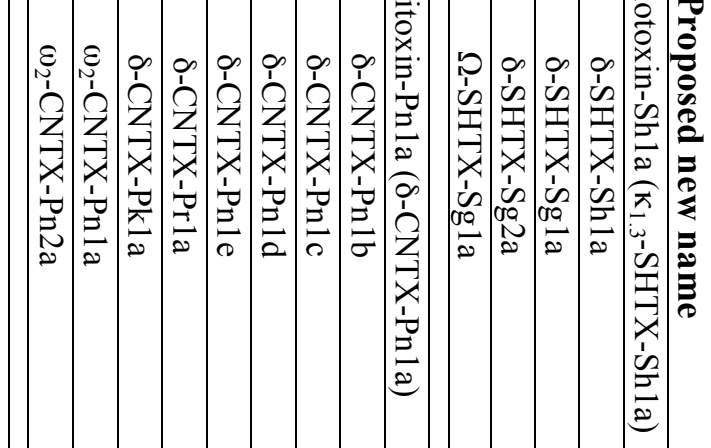

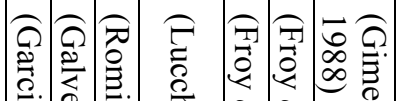

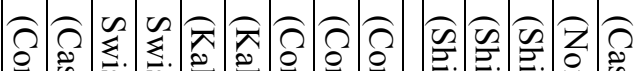

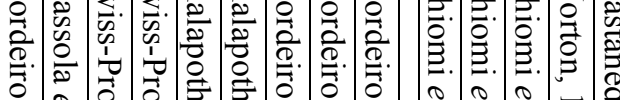
:

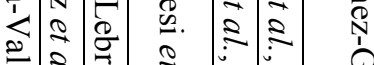

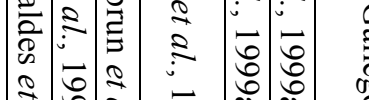
至

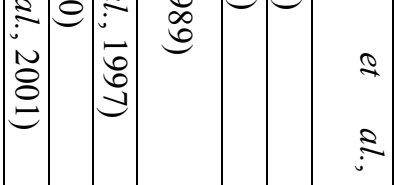

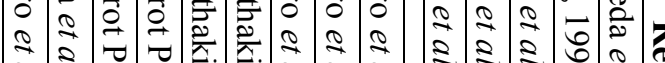

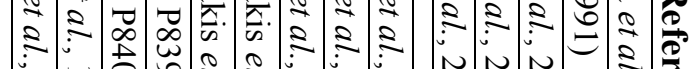

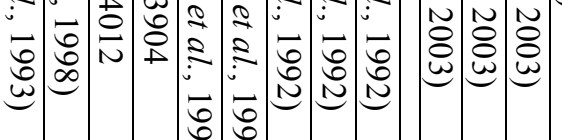
$\begin{array}{lll}\overrightarrow{0} & \overrightarrow{0} \\ 0 & 0 \\ 0 & 0 \\ 0\end{array}$ 
Figure 1
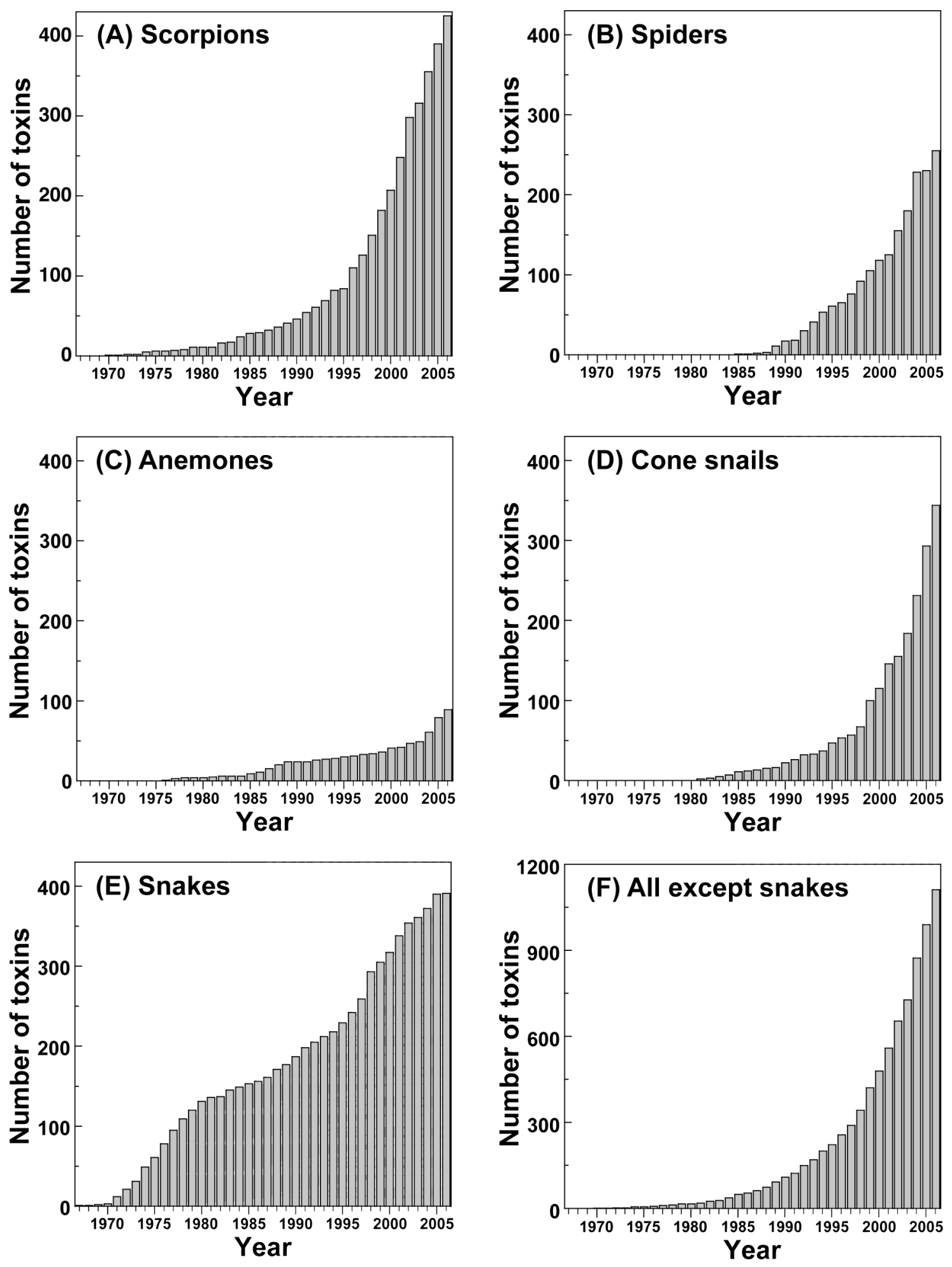
Figure 2

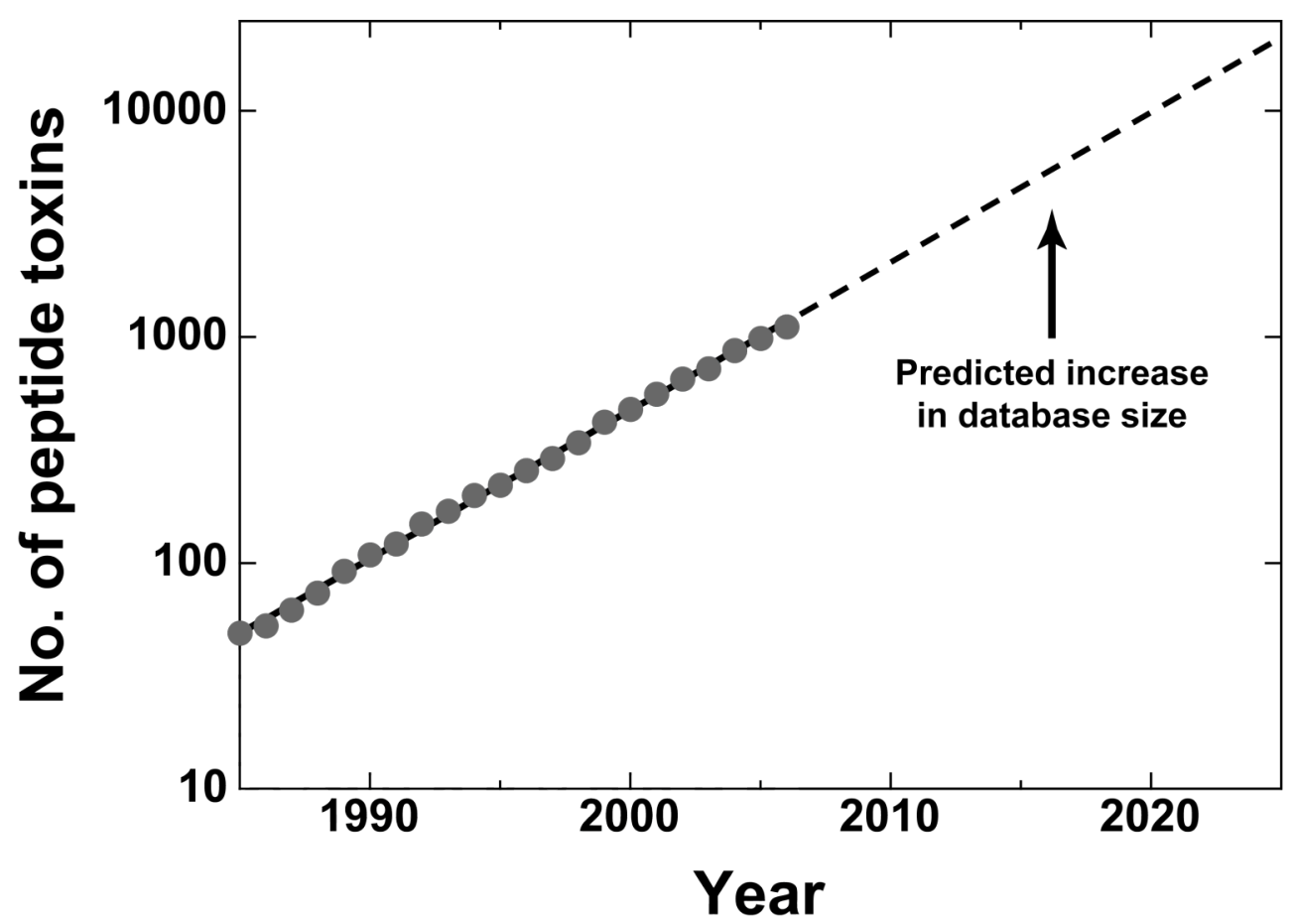


Figure 3

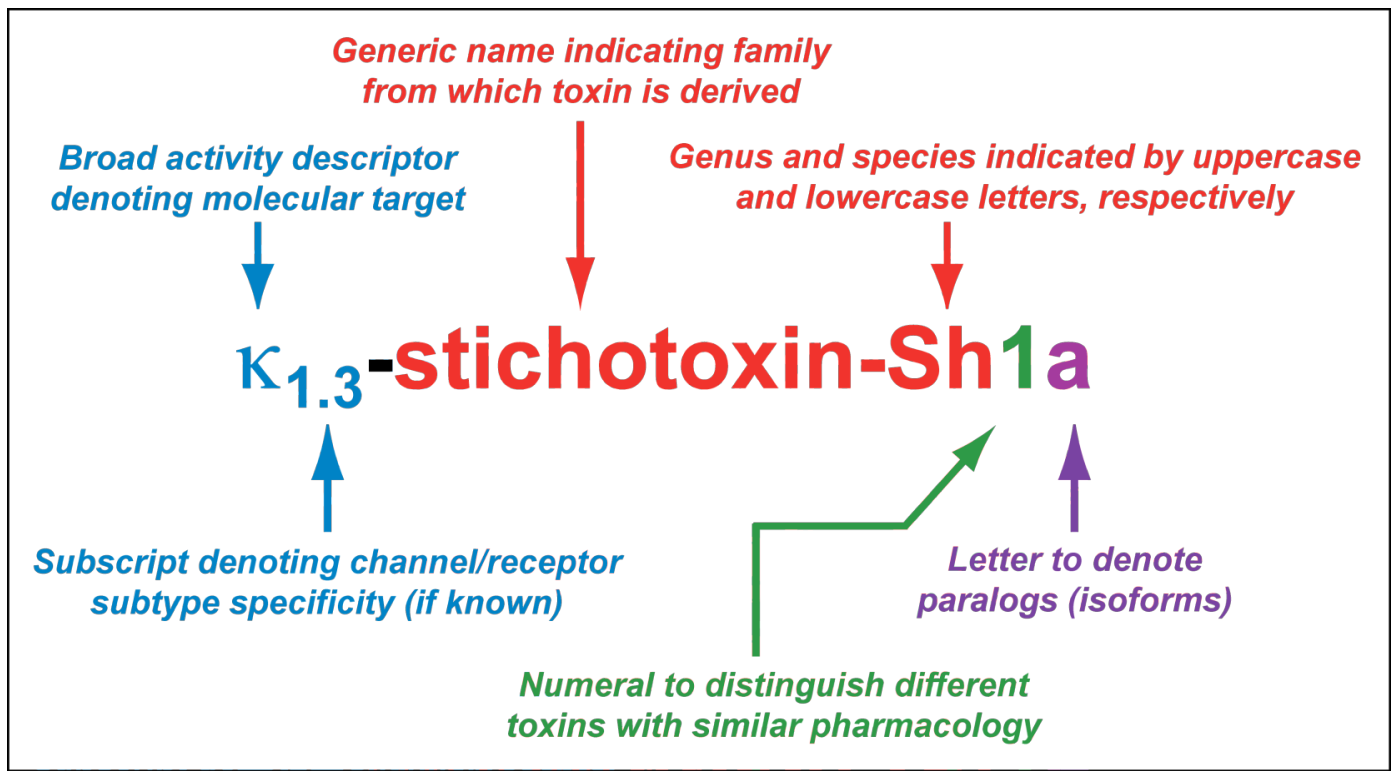

Figure 4

\begin{tabular}{|c|c|c|}
\hline Old name & Primary structure & Proposed name \\
\hline$\delta-A C T X-H v 1 a$ & CAKKRNWCGKTEDCCCPMKCVYAWYNEQGSCQSTISALWKKC & $\delta$-hexatoxin-Hv1a \\
\hline Magi-14 & CARKRAWCEKTENCCCPMKCIYAWYNGQSSCDHTISTIWTSC & $\delta$-hexatoxin-Mg1a \\
\hline
\end{tabular}




\section{Supplementary Data}

Tables 1-4 summarize the proposed generic toxin names, and their corresponding abbreviations, for all families of scorpions, sea anemones, snakes, and spiders, respectively. Note that these tables are reproduced online for easy look-up at http://www.venomics.org/nomenclature.

Table 1: Generic names for peptide toxins from scorpions ${ }^{1}$

\begin{tabular}{|c|l|l|c|}
\hline Family No. & Family Name & Generic toxin name & Toxin abbreviation \\
\hline $\mathbf{1}$ & Bothriuridae & Bothritoxin & BTTX \\
\hline $\mathbf{2}$ & Buthidae & Buthitoxin & BUTX \\
\hline $\mathbf{3}$ & Chactidae & Chactitoxin & CHTX \\
\hline $\mathbf{4}$ & Chaerilidae & Chaeritoxin & CETX \\
\hline $\mathbf{5}$ & Diplocentridae & Diplotoxin & DLTX \\
\hline $\mathbf{6}$ & Euscorpiidae & Euscotoxin & ESTX \\
\hline $\mathbf{7}$ & Hemiscorpiidae & Hemiscorpitoxin & HMTX \\
\hline $\mathbf{8}$ & Heteroscorpionidae & Heteroscorpitoxin & HSTX \\
\hline $\mathbf{9}$ & luridae & luritoxin & IRTX \\
\hline $\mathbf{1 0}$ & Liochelidae & Liotoxin & LITX \\
\hline $\mathbf{1 1}$ & Microcharmidae & Microcharmitoxin & MCTX \\
\hline $\mathbf{1 2}$ & Pseudochactidae & Pseudochactitoxin & PCTX \\
\hline $\mathbf{1 3}$ & Scorpionidae & Scorpionitoxin & SNTX \\
\hline $\mathbf{1 4}$ & Scorpiopidae & Scorpiotoxin & SPTX \\
\hline $\mathbf{1 5}$ & Superstitioniidae & Stitiotoxin & SSTX \\
\hline $\mathbf{1 6}$ & Troglotayosicidae & Troglotoxin & TGTX \\
\hline $\mathbf{1 7}$ & Urodacidae & Urodatoxin & UDTX \\
\hline $\mathbf{1 8}$ & Vaejovidae & Vaejotoxin & VJTX \\
\hline
\end{tabular}

${ }^{1}$ Note that the higher-level taxonomy of scorpions (Animalia: Arthropoda: Chelicerata: Arachnida: Scorpiones) is controversial and susceptible to future revision. We have therefore used the expanded 18family set proposed by Prendini and Wheeler (Prendini and Wheeler, 2005) rather than the reduced 13family set proposed by Fet and Soleglad (Fet and Soleglad, 2005). This choice is not intended to reflect on the relative merits of the two different taxonomic classifications but rather is intended to minimize future revisions of scorpion toxin nomenclature. No future revisions will be required if the P\&W model proves to be correct. If the F\&S model proves correct, the worst-case scenario is that two or more generic toxin names might be associated with a given scorpion family. However, we determined that this would be a better situation than if we had chosen the F\&S model and the P\&W model ultimately proves correct. In this scenario, new generic names would have to be created and a large number of scorpion toxin names would need to be revised. 
Table 2: Generic names for peptide toxins from sea anemones ${ }^{1}$

\begin{tabular}{|c|c|c|c|}
\hline Family No. & Family Name & Generic toxin name & Toxin abbreviation \\
\hline 1 & Acontiophoridae & Acontiophoritoxin & APTX \\
\hline 2 & Actinernidae & Actinetoxin & AETX \\
\hline 3 & Actiniidae & Actitoxin & AITX \\
\hline 4 & Actinodendronidae & Dendronitoxin & DNTX \\
\hline 6 & Actinoscyphiidae & Scyphitoxin & SCTX \\
\hline 7 & Actinostolidae & Stolitoxin & SOTX \\
\hline 8 & Aiptasiidae & Aiptatoxin & ATTX \\
\hline 9 & Aiptasiomorphidae & Ptasiotoxin & PSTX \\
\hline 10 & Aliciidae & Alicitoxin & ALTX \\
\hline 11 & Andresiidae & Andretoxin & ADTX \\
\hline 12 & Andwakiidae & Andwatoxin & AWTX \\
\hline 13 & Aurelianidae & Aureliatoxin & AUTX \\
\hline 14 & Bathyphelliidae & Bathytoxin & BHTX \\
\hline 15 & Boloceroididae & Bolotoxin & BLTX \\
\hline 16 & Condylanthidae & Condytoxin & CYTX \\
\hline 17 & Diadumenidae & Diatoxin & DITX \\
\hline 18 & Discosomidae & Discotoxin & DCTX \\
\hline 19 & Edwardsiidae & Edwarditoxin & EWTX \\
\hline 20 & Exocoelactiidae & Coelatoxin & COTX \\
\hline 21 & Galatheanthemidae & Galatoxin & GLTX \\
\hline 22 & Gonactiniidae & Gonatoxin & GNTX \\
\hline 23 & Halcampidae & Halatoxin & HATX \\
\hline 24 & Halcampoididae & Campotoxin & CATX \\
\hline 25 & Halcuriidae & Halcutoxin & HCTX \\
\hline 26 & Haliactiidae & Haliatoxin & HLTX \\
\hline 27 & Haliplanellidae & Planellitoxin & PNTX \\
\hline 28 & Haloclavidae & Clavitoxins & CVTX \\
\hline 29 & Hormathiidae & Hormotoxin & HRTX \\
\hline 30 & Ilyanthidae & Ilyatoxins & IYTX \\
\hline 31 & Isoactiidae & Isoactitoxin & ISTX \\
\hline 32 & Isanthidae & Isanthooxin & INTX \\
\hline 33 & Isophelliidae & Isophellitoxin & IPTX \\
\hline 34 & Limnactiniidae & Limnatoxin & LMTX \\
\hline 35 & Liponematidae & Liponotoxin & LNTX \\
\hline 36 & Metridiidae & Metritoxin & MTTX \\
\hline 37 & Minyadidae & Minyatoxin & MYTX \\
\hline 38 & Nemanthidae & Nemanthitoxin & NTTX \\
\hline 39 & Nevadneidae & Nevatoxin & NVTX \\
\hline 40 & Octineonidae & Octinotoxin & OTTX \\
\hline 41 & Paractidae & Paratoxin & PRTX \\
\hline 42 & Phymanthidae & Phymatoxin & PMTX \\
\hline 43 & Preactiidae & Preactitoxin & PATX \\
\hline 44 & Ptychodactiidae & Dactitoxin & DATX \\
\hline 45 & Sagartiidae & Sagatoxin & SATX \\
\hline 46 & Sagartiomorphidae & Sagartitoxin & STTX \\
\hline 47 & Stichodactylidae & Stichotoxin & SHTX \\
\hline 48 & Thalassianthidae & Thalatoxin & TATX \\
\hline
\end{tabular}

${ }^{1}$ Animalia: Cnidaria: Anthozoa: Hexacorallia: Actiniaria. Taxonomy is taken from the Integrated Taxonomic Information System (http://www.itis.gov/index.html). 
Table 3: Generic names for peptide toxins from snakes ${ }^{1}$

\begin{tabular}{|c|c|c|c|}
\hline Family No. & Family name & Generic toxin name $^{2}$ & Toxin Abbreviation \\
\hline 1 & Acrochordidae & Acrotoxin & ARTX \\
\hline 2 & Aniliidae & Anilitoxin & ANTX \\
\hline 3 & Anomalepididae & Anomatoxin & AMTX \\
\hline 4 & Anomochilidae & Chilitoxin & CITX \\
\hline 5 & Atractaspididae & Atractasptoxin & ASTX \\
\hline 6 & Boidae & Boidatoxin & BDTX \\
\hline 7 & Bolyeriidae & Bolyeritoxin & BRTX \\
\hline 8 & Colubridae & Colubritoxin & CLTX \\
\hline 9 & Cylindrophiidae & Cylindrotoxin & CDTX \\
\hline 10 & Elapidae & Elapitoxin & EPTX \\
\hline 1 & Leptotyphlopidae & Leptotoxin & LTTX \\
\hline 12 & Loxocemidae & Loxotoxin & LXTX \\
\hline 13 & Pythonidae & Pythotoxin & PYTX \\
\hline 14 & Tropidophiidae & Tropidotoxin & TPTX \\
\hline 15 & Typhlopidae & Typhlotoxin & TYTX \\
\hline 16 & Uropeltidae & Uropetoxin & UPTX \\
\hline 17 & Viperidae & Viperitoxin & VPTX \\
\hline 18 & Xenopeltidae & Xenotoxin & XNTX \\
\hline
\end{tabular}

${ }^{1}$ Animalia: Chordata: Vertebrata: Reptilia: Squamata: Serpentes. Taxonomy is taken from the Integrated Taxonomic Information System (http://www.itis.gov/index.html).

${ }^{2}$ While a small subset of snakes have traditionally been classified as "non-venomous", recent work on evolution of the venom apparatus in squamates (Fry et al., 2006) indicates that some of these snakes may nonetheless possess rudimentary venom glands and produce peptide toxins. Thus, we have provided generic names for all snake families. 
Table 4: Generic names for peptide toxins from spiders ${ }^{1}$

\begin{tabular}{|c|c|c|c|}
\hline Family No. & Family Name & Generic toxin name & Toxin abbreviation \\
\hline 1 & Actinopodidae & Actinopoditoxin & AOTX \\
\hline 2 & Agelenidae & Agatoxin & AGTX \\
\hline 3 & Amaurobiidae & Amaurobitoxin & AMATX \\
\hline 4 & Ammoxenidae & Ammoxotoxin & AXTX \\
\hline 5 & Amphinectidae & Amphinetoxin & APHTX \\
\hline 6 & Anapidae & Anapitoxin & ANPTX \\
\hline 7 & Antrodiaetidae & Antrotoxin & ATRTX \\
\hline 8 & Anyphaenidae & Anyphaetoxin & APHTX \\
\hline 9 & Araneidae & Aranetoxin & AATX \\
\hline 10 & Archaeidae & Archaetoxin & ARCTX \\
\hline 11 & Atypidae & Atypitoxin & ATPTX \\
\hline 12 & Austrochilidae & Austrotoxin & OZTX \\
\hline 13 & Barychelidae & Barytoxin & BATX \\
\hline 14 & Caponiidae & Capotoxin & CPTX \\
\hline 15 & Chummidae & Chummitoxin & CMTX \\
\hline 16 & Cithaeronidae & Cithaerotoxin & CTTX \\
\hline 17 & Clubionidae & Clubiotoxin & CBTX \\
\hline 18 & Corinnidae & Corinnitoxin & CRTX \\
\hline 19 & Ctenidae & Ctenitoxin & CNTX \\
\hline 20 & Ctenizidae & Ctenizitoxin & CZTX \\
\hline 21 & Cyatholipidae & Cyathotoxin & CYTTX \\
\hline 22 & Cybaeidae & Cybaetoxin & CYBTX \\
\hline 23 & Cycloctenidae & Cyclotoxin & CYCTX \\
\hline 24 & Cyrtaucheniidae & Cyrtautoxin & CUTX \\
\hline 25 & Deinopidae & Deinotoxin & DOTX \\
\hline 26 & Desidae & Desitoxin & DSTX \\
\hline 27 & Dictynidae & Dictytoxin & DTTX \\
\hline 28 & Diguetidae & Diguetoxin & DGTX \\
\hline 29 & Dipluridae & Dipluritoxin & DPTX \\
\hline 30 & Drymusidae & Drymutoxin & DMTX \\
\hline 31 & Dysderidae & Dysdetoxin & DDTX \\
\hline 32 & Eresidae & Eretoxin & ERTX \\
\hline 33 & Filistatidae & Filistatoxin & FLTX \\
\hline 34 & Gallieniellidae & Gallitoxin & GATX \\
\hline 35 & Gnaphosidae & Gnaphotoxin & GPTX \\
\hline 36 & Gradungulidae & Gradutoxin & GDTX \\
\hline 37 & Hahniidae & Hahnitoxin & HNTX \\
\hline 38 & Hersiliidae & Hersitoxin & HITX \\
\hline 39 & Hexathelidae & Hexatoxin & HXTX \\
\hline 40 & Holarchaeidae & Holarchatoxin & HHTX \\
\hline 41 & Homalonychidae & Homatoxin & HOTX \\
\hline 42 & Huttoniidae & Huttotoxin & HUTX \\
\hline 43 & Hypochilidae & Hypotoxin & HPTX \\
\hline 44 & Idiopidae & Idiotoxin & IDTX \\
\hline 45 & Lamponidae & Lampotoxin & LATX \\
\hline 46 & Leptonetidae & Leptotoxin & LPTX \\
\hline 47 & Linyphiidae & Linytoxin & LYTX \\
\hline 48 & Liocranidae & Liocratoxin & LRTX \\
\hline 49 & Liphistiidae $^{2}$ & - & - \\
\hline 50 & Lycosidae & Lycotoxin & LCTX \\
\hline 51 & Malkaridae & Malkatoxin & MKTX \\
\hline 52 & Mecicobothriidae & Mecitoxin & MBTX \\
\hline 53 & Mecysmaucheniidae & Mauchetoxin & MUTX \\
\hline 54 & Micropholcommatidae & Microphotoxin & MPTX \\
\hline
\end{tabular}




\begin{tabular}{|c|c|c|c|}
\hline 55 & Microstigmatidae & Microstigmatoxin & MCSTX \\
\hline 56 & Migidae & Migitoxin & MITX \\
\hline 57 & Mimetidae & Mimetoxin & MMTX \\
\hline 58 & Miturgidae & Miturgitoxin & MGTX \\
\hline 59 & Mysmenidae & Menidatoxin & MDTX \\
\hline 60 & Nemesiidae & Nemetoxin & NETX \\
\hline 61 & Nephilidae & Nephitoxin & NPTX \\
\hline 62 & Nesticidae & Nestitoxin & NSTX \\
\hline 63 & Nicodamidae & Nicotoxin & NCTX \\
\hline 64 & Ochyroceratidae & Ochyrotoxin & ORTX \\
\hline 65 & Oecobiidae & Oecotoxin & OCTX \\
\hline 66 & Oonopidae & Oonotoxin & ONTX \\
\hline 67 & Orsolobidae & Orsotoxin & OSTX \\
\hline 68 & Oxyopidae & Oxotoxin & OXTX \\
\hline 69 & Palpimanidae & Palpitoxin & PPTX \\
\hline 70 & Pararchaeidae & Pararchatoxin & PRCTX \\
\hline 71 & Paratropididae & Paratrotoxin & PTTX \\
\hline 72 & Periegopidae & Peritoxin & PETX \\
\hline 73 & Philodromidae & Philotoxin & POTX \\
\hline 74 & Pholcidae & Pholcitoxin & PHTX \\
\hline 75 & Phyxelididae & Phyxetoxin & PXTX \\
\hline 76 & Pimoidae & Pimotoxin & PITX \\
\hline 77 & Pisauridae & Pisautoxin & PSTX \\
\hline 78 & Plectreuridae & Plectoxin & PLTX \\
\hline 79 & Prodidomidae & Proditoxin & PDTX \\
\hline 80 & Psechridae & Psechritoxin & PSRTX \\
\hline 81 & Salticidae & Saltitoxin & SLTX \\
\hline 82 & Scytodidae & Scytotoxin & SYTX \\
\hline 83 & Segestriidae & Segestritoxin & SGTX \\
\hline 84 & Selenopidae & Seletoxin & SETX \\
\hline 85 & Senoculidae & Senocutoxin & SUTX \\
\hline 86 & Sicariidae & Sicaritoxin & SCRTX \\
\hline 87 & Sparassidae & Sparatoxin & SPRTX \\
\hline 88 & Stenochilidae & Stenotoxin & STNTX \\
\hline 89 & Stiphidiidae & Stiphiditoxin & SDTX \\
\hline 90 & Symphytognathidae & Symphytoxin & SMTX \\
\hline 91 & Synaphridae & Synaphritoxin & SYNTX \\
\hline 92 & Synotaxidae & Synotaxitoxin & SXTX \\
\hline 93 & Telemidae & Teletoxin & TETX \\
\hline 94 & Tengellidae & Tengellitoxin & TNGTX \\
\hline 95 & Tetrablemmidae & Tetrabletoxin & TBTX \\
\hline 96 & Tetragnathidae & Tetratoxin & TTTX \\
\hline 97 & Theraphosidae & Theraphositoxin & TRTX \\
\hline 98 & Theridiidae & Theriditoxin & TDTX \\
\hline 99 & Theridiosomatidae & Theridiotoxin & THTX \\
\hline 100 & Thomisidae & Thomitoxin & TMTX \\
\hline 101 & Titanoecidae & Titanotoxin & TNTX \\
\hline 102 & Trechaleidae & Trechaletoxin & TLTX \\
\hline 103 & Trochanteriidae & Trochantoxin & TCTX \\
\hline 104 & Uloboridae $^{2}$ & - & - \\
\hline 105 & Zodariidae & Zodatoxin & ZDTX \\
\hline 106 & Zoridae & Zoritoxin & ZRTX \\
\hline 107 & Zorocratidae & Zorocratoxin & ZCTX \\
\hline 108 & Zoropsidae & Zoropsitoxin & ZPTX \\
\hline
\end{tabular}

${ }^{1}$ Animalia: Arthropoda: Chelicerata: Arachnida: Araneae. Taxonomy is taken from the World Spider Catalog (http://research.amnh.org/entomology/spiders/catalog/) (Platnick, 1997).

${ }^{2}$ Uloboridae and Liphistiidae lack venom glands and thus do not produce peptide toxins. 